\title{
Major Geological Fissure through Prehistoric Lion Monument at Giza Inspired Split Lion Hieroglyphs and Ancient Egypt's Creation Myth
}

\author{
Manu Seyfzadeh, Robert M. Schoch \\ Institute for the Study of the Origins of Civilization, College of General Studies, Boston University, Boston, MA, USA \\ Email:manu@cheopspyramid.com, schoch@bu.edu
}

How to cite this paper: Seyfzadeh, M., \& Schoch, R. M. (2019). Major Geological Fissure through Prehistoric Lion Monument at Giza Inspired Split Lion Hieroglyphs and Ancient Egypt's Creation Myth. Archaeological Discovery, 7, 211-256. https://doi.org/10.4236/ad.2019.74011

Received: August 5, 2019

Accepted: August 30, 2019

Published: September 2, 2019

Copyright () 2019 by author(s) and Scientific Research Publishing Inc. This work is licensed under the Creative Commons Attribution International License (CC BY 4.0).

http://creativecommons.org/licenses/by/4.0/

\section{Open Access}

\begin{abstract}
In search of textual references to a monumental lion at Giza predating the Old Kingdom, we focused our investigation on the earliest use of three ancient Egyptian hieroglyphs depicting the frontal and caudal halves of a lion and a fissure-like symbol. These symbols first appear in Egypt's proto- and early dynastic era and form part of Egypt's earliest known set of written language symbols. During the First Dynasty, these symbols were both carved into ivory tags and painted onto jars to designate the quality of oil shipped as grave goods to both royal and private tombs. The same iconography and symbols appear in the creation story recorded on the frieze and upper register of the Edfu Temple's enclosure wall, where the frontal and caudal animal parts are used to name two of seven personified creation words, the so-called $\underline{d} 3 j s w^{1}$, uttered during the act of creating the world from the primordial flood Mehit-wrt by Ptah. Here, we show that the appearance of such unusual icons in such different contexts can be explained by a prominent physical feature (a geological fissure) affecting the appearance of the Great Sphinx, thus demonstrating that the original monument including this feature existed before these hieroglyphs were invented. We have previously argued that the Great Sphinx was remodeled from the much older monumental lioness Mehit. Here, we provide further evidence that this monument existed in the form of a lion or lioness at least seven centuries before the time of Khafre (circa 2500 B.C.E.) challenging the conventional model which attributes the original creation of the Great Sphinx to this Old Kingdom ruler.
\end{abstract}

\section{Keywords}

Great Sphinx, Giza, Lioness, Mehit, Buto-Maadi, Sumer, Edfu, JAW Sign

\footnotetext{
${ }^{1}$ In this paper, we use the standard Egyptological consonants-only phonetic transliteration method with inferred vowel sounds in between omitted, except for widely known names. $\underline{d} 3 j s w$, for example, may have been pronounced "Jai-soo". For the full transliteration set of all known Egyptian consonants used see Allen, 2014: pp. 18-20.
} 


\section{Introduction}

The original creation of the Great Sphinx monument on the Giza Plateau (Egypt) is commonly attributed to the fourth king of ancient Egypt's Fourth Dynasty, Khafre and is consequently dated to circa 2500 B.C.E. (Reisner, 1912: p. 13; Hassan, 1949: p. 88; Ricke, 1970: p. 32; Lehner, 1991: pp. 405-411; Hawass, 1993: pp. 180-182; Lehner \& Hawass, 2017: pp. 240-241). This orthodox historical model has been challenged by geological data (Schoch, 1992; Dobecki \& Schoch, 1992; West \& Schoch in NBC, 1993; Reader, 1997: p. 13; Schoch in Schoch \& Bauval, 2017, appendices 6 and 7), astronomical evidence (Bauval in Schoch \& Bauval, 2017, chapter 6), archeological data (Stadlemann, 2000; Dobrev, 2004), and textual evidence (Seyfzadeh et al., 2017; Seyfzadeh \& Schoch, 2018), yet it continues to shape the main-stream narrative presented in major published media and academic circles. The alternative model based on this cumulative contrarian evidence proposes that an Old Kingdom ruler, for example Sneferu, Khufu, Djedefre, or Khafre, merely remodeled a much older, then circa 7000- to 8000-year old, already severely weathered stony lion (or lioness) statue at Giza into the Great Sphinx lion-human chimera we know today.

Despite the compelling nature of textual evidence, our investigations into Egyptological proof of an older Sphinx are naturally limited to that time interval before the time of Khafre, i.e. from circa 3300 to 2500 B.C.E., during which the ancient Egyptians are known to already have used symbols in writing, unlike is the case with other archeological, geological, and astronomical evidence which can reach back much further in time. Hence, our investigative focus on textual evidence aims to compellingly falsify the orthodox model with such written proof rather than to positively identify the date of the first time when the core body of the Great Sphinx and associated temples and causeway may have been carved and built from the limestone rock forming most of the Giza Plateau. Such a distant prehistoric time for the original carving of this monument, as suggested by the lines of evidence cited above, precedes the currently known advent of writing in the Nile Valley and Delta by thousands of years. In other words, any written reference to a megalithic lion monument at Giza dated to a time before the reign of Khafre, while not indicative of the date of its original creation, nevertheless powerfully falsifies the orthodox model with recorded evidence handed to us by the ancient Egyptians themselves and neutralizes most if not all of the other, less compelling, archeological or conjectural evidence brought forth in support of the Reisner/Hassan/Ricke/Lehner/Hawass model which proposes that Khafre was its original builder.

For example, the Inventory Stele explicitly states that Khafre's father Khufu repaired this monument, directly contradicting the idea that Khafre originally created the Great Sphinx. Even though the authenticity of the text inscribed on the stele has been put in question, we have concluded that most, if not all, of the criticisms against it are either inaccurate or imprecise (Seyfzadeh \& Schoch, 2018). The story told on the stele, even if authentic as we have argued, however 
does not falsify the more general historical model held by most historians and Egyptologists that the monument was likely still made sometime during the large megalithic Pyramid Age (Circa 2670-2450 B.C.E.), i.e. during the Third and Fourth Dynasty of the early Old Kingdom era, for example by Sneferu, Khufu's father, or even an earlier king of the Third Dynasty.

In another prior publication, nevertheless, we further pushed back the time of the earliest identifiable textual trace referring to a monumental lioness at Giza known as Mehit to the First Dynasty's Horus Djer (Seyfzadeh et al., 2017), the third king of a unified Egypt probably alive circa 2900 B.C.E., and, considering the earliest appearance of Mehit on sealings associated with unified Egypt's first king Horus Narmer, to a time five centuries before Khafre, i.e. circa 3000 B.C.E. Therefore, we have concluded that the core body of the Great Sphinx existed before the megalithic Pyramid Age of the early Old Kingdom in the form of a female lion the early dynastic Egyptians (First and Second Dynasty) knew as Mehit.

Here, we now present new textual evidence dating this primordial monument (later remodeled to become the Great Sphinx) even further back to the predynastic era before the unification of Upper and Lower Egypt by Horus Narmer, further solidifying our case that the orthodox model cannot be correct. Our evidence shows that the monument existed at least seven centuries before Khafre and before the known advent of fully developed writing in ancient Egypt. We conclude that the physical appearance of the megalithic lion (or lioness) at Giza may indeed have substantially influenced the later culture of the pre-historic and proto-dynastic Egyptians with respect to such diverse pillars of civilization as documenting economic transactions with written language and the theological myth of the creation of the world.

\section{Observations and Results}

Split Lion Symbols. We focused our attention on three hieroglyphs shown in Figure 1. The earliest attested of the three, Gardiner F22 depicting the hind (caudal) portion of a lion or other feline animal was first discovered in tomb B2 of the predynastic ruler Jrj-Hor (circa 3100 B.C.E.; Kahl, 1994: p. 496; Kaiser \& Dreyer, 1982: p. 234a), the owner of the first and presumably oldest double tomb (B1/2) in Umm El-Qa'ab's cemetery B marking the transition from the earlier (i.e. more northeastern) single tombs of cemetery U (Helck, 1987: pp. 90-91), where the oldest known written symbols of Egypt were discovered in Scorpion I's tomb U-j (circa 3300-3200 B.C.E.; Dreyer, 1998). The other two, Gardiner F4 and F25, frontal lion and donkey leg respectively, are first attested in the First Dynasty in Horus Narmer's double tomb B17/18 (Kahl, 1994: p. 491) and the tombs B-o, B-z, and B-y of Horus Djer (circa 3000 B.C.E.), Djet (circa 2980 B.C.E.), and Merineith (circa 2950 B.C.E.; Kahl, 1994: p. 496). These three symbols, therefore, are part of the earliest known set of Egyptian hieroglyphs.

Oil Quality. The material cultural context in which these symbols were found are inscribed tags made from ivory (Figure 2) or wood, and ink-painted jars 


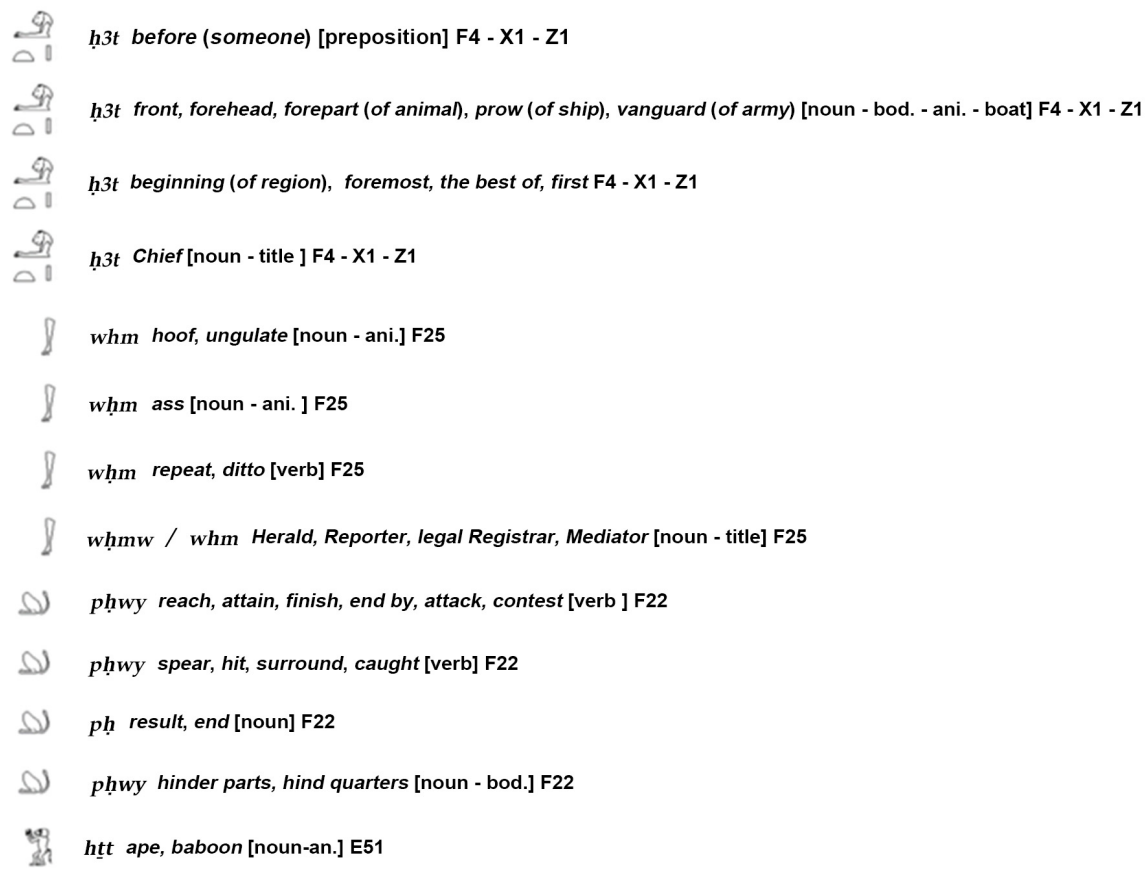

Figure 1. A compilation of translations of the Egyptian hieroglyphic symbols Gardiner F4, F22, and F25 from Vygus, 2015. The word for oil, h. $3 t . t$ is derived from h3t front/first alluding to the first effluent fraction from the pressing of the substrate fruit containing a higher content of the aromatic fruit oil. Semantically and linguistically related to h $3 t . t$ is Gardiner E51 $h \underline{t} \underline{t}$, one of the Egyptian words for baboon possibly alluding to the fact that males of this animal issue the so-called morning "wahoo" when the Sun first appears.

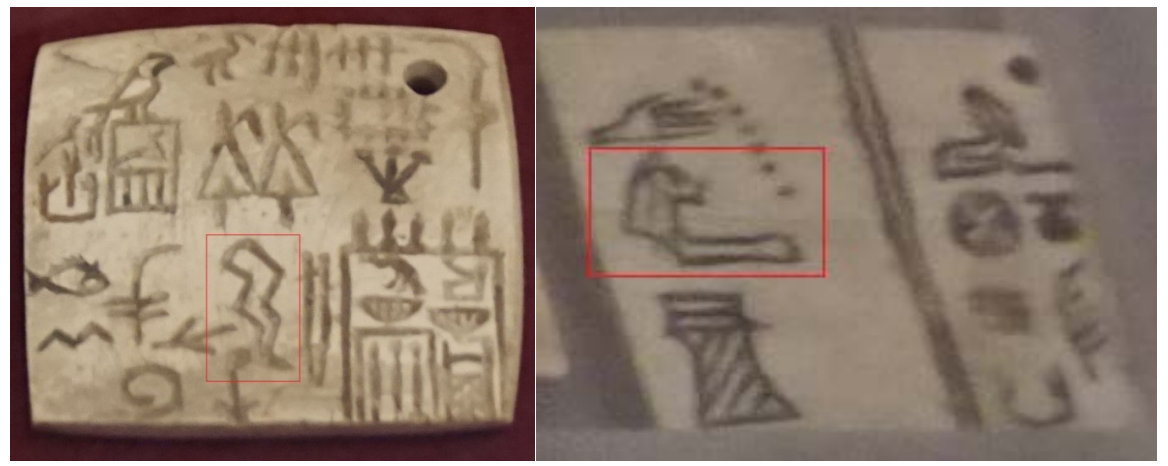

Figure 2. The left pane shows an ivory oil tag dated to the First Dynasty (circa 3000-2800 B.C.E.) and the reign of Horus Djet. The king is depicted followed by his highest official $S \underline{d} k 3$ presumably inaugurating statues or shrines to an Ibis $h b j$ and two Lotuses $z \dot{s} n j$, planning $h 3$ (note the corresponding symbol Gardiner M16 below the hole in the right upper corner) the building of a (double walled) cellar hntj and staying aha at the palace $h w t$ nbj of the two mistresses. The oil grade is given as intermediate/repeat F25 (see Results), the quantity is 1100 fruit branches, and the origin of the oil is the south of Egypt. In the right pane, we show an example of first grade hand purification oil designated with Gardiner F4. Cairo Museum, photos by M.S., September 2018.

(Figure 3) where they designated the quality of an ancient luxury item, namely oil, shipped to royal and private tombs in Abydos and Saqqara, for example, as grave goods for the afterlife. F4 designated the best, prime, or first (i.e. h. 3 t.t, 


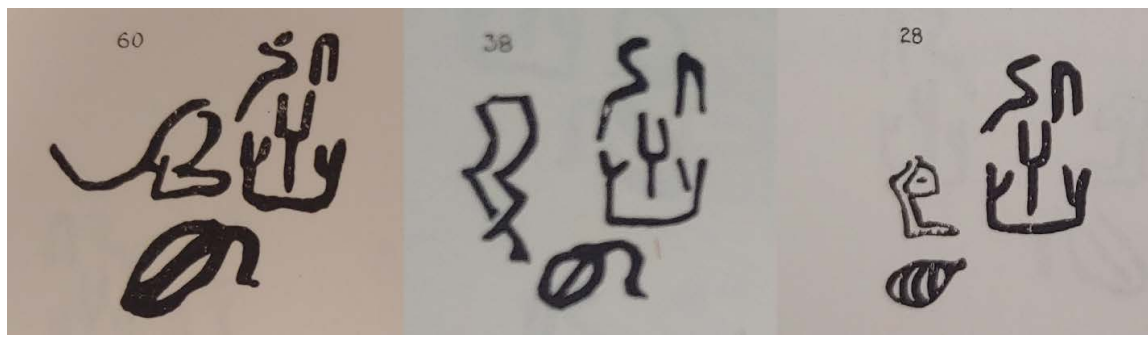

Figure 3. Examples of painted oil designations on jars of type C6 showing Gardiner F4 (right, 28) F22 (left, 60), and either F25 (middle, 38) or an unknown symbol resembling a fissure or lightning. With 38 , we show the only example from several sources which closely resembles a hooved leg. The name on all three is the high official of Horus Djet, $S d k 3$, and the symbol at the bottom designates an unknown fruit (possibly a tiger-nut or an olive) from which the oil was pressed. Photo montage by M.S. from Emery, 1954, Fig.'s 140-142).

"front") effluent fraction of the oil press, F22 designated the last, inferior effluent fraction (i.e. $p h$ "end"), and F25 either designated an intermediate fraction or the lowest quality repeat-fraction (i.e. $u \mathrm{hm}$ "repeat"; Figure 3; see discussion by Helck, 1987: pp. 171, 173, and 175).

At this point, we would like to interject an alternative interpretation for the symbol previously read as "donkey leg" in this context. The symbol in Figure 2, left pane, has four bends which is not consistent with the three articulations of the leg of an animal, donkey or otherwise. Instead, we think this symbol depicts a crack, split, fissure, or lightning-like figure which might date the first-attested use further back to tombs U-546 and U-j (Figure 4) where a similar symbol can be seen in association with a half-moon like crescent sign on a jar and two bone tags (Dreyer, 1998, Tafel/Plate 33, \#142-143). It is possible that the crescent stands for $h u^{\prime}$ (tiger-nut), and that this jar (Figure 4) contained an intermediate quality of oil from that fruit. This would explain why the symbol is seen on an oil tag attached to jars found in the royal tombs of Horus Djer, Merineith, and Horus Djet. An intermediate quality effluent fraction designated by a "fissure" symbol is more consistent with this context than a poor-quality repeat-press fraction unlikely to be shipped to a royal tomb.

Furthermore, while the symbol occurs side-by-side with F4 in S3504-Q (Helck, 1987: p. 175), and possibly indicated a mixed fraction of "front" and "intermediate", F22 almost always occurs in the context of private tombs likely because of its lower quality and supposedly only twice in a royal tomb context (Helck, 1987: p. 173). The first of these two supposed exceptions is an ebony tablet from the tomb complex of Horus Djer showing a full couchant lion next to a building with three baboons. This piece, contra Helck, may not be an oil tag at all since it contains none of the other identifying characteristics typically seen (Petrie, 1901, Plate Va, 13; see also Figure 20 below under Discussion). The second supposed exception is a wooden fragment (Petrie, 1901, Plate Va, 2) on which a lion, front or back, is impossible to make out to the left of the building on the right end of the piece with three squares inside. Instead, the carved 

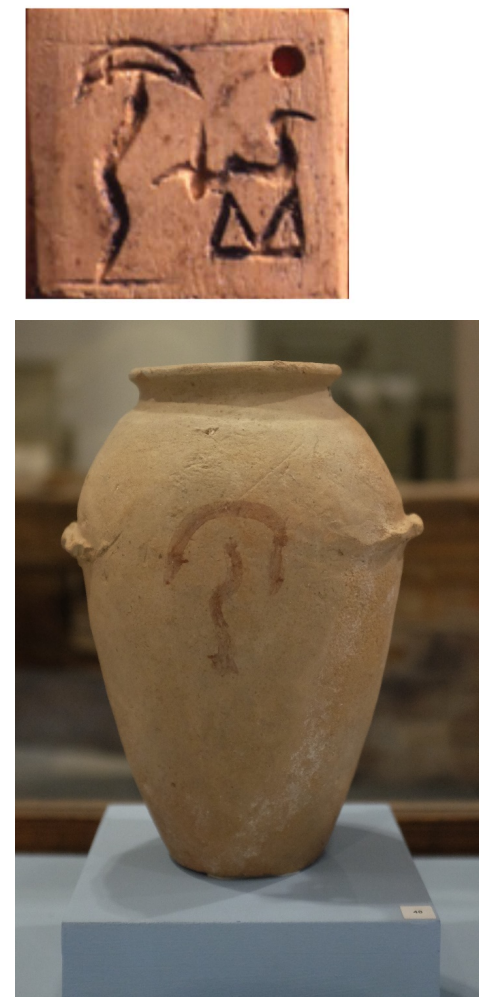

Figure 4. The top pane shows a bone tag from Tomb U-j (circa 3300-3200 B.C.E.). Image:

https://upload.wikimedia.org/wikipedia/commons/5/57/Design_of_th e_Abydos_token_glyphs_dated_to_3400-3200_BCE.jpg, courtesy of Günther Dreyer; modified. Bottom pane, Class W wavy-handled prehistoric pottery jar discovered in predynastic grave U-546 from $A b$ ydos cemetery $\mathrm{U}$ showing the same crescent and "fissure". Cairo $\mathrm{Mu}$ seum; photo by R.M.S., June 2019; modified.

symbols may be the commonly seen falcon-hobble-throne triad, which Helck interprets to be a native-Buto spelling of "Horus Tree Garden" (Helck, 1987: p. 171-172).

We therefore propose that the "split-symbol" used on oil tags and jars is not the donkey leg F25, but a "fissure"-depicting symbol designating intermediate-quality oil from a fraction in between h3t.t (F4, "front") and ph (F22, "end"). This also explains, why the symbol may have been written with varying numbers of bends and logically places it between the frontal and caudal halves of a lion.

The typical content recorded on the ivory tags was an account of significant events during a given year experienced by the reigning king not unlike the entrees in the registers of the Royal Annals of Ancient Egypt, and the amount and origin of the oil shipped besides the aforementioned quality designation (Helck, 1987: p. 173). On ink-painted jars, the name of the royal agricultural estate director is given ( $S d k 3$ in the three examples in Figure 3 ) and the fruit is shown from which the oil was pressed. 
Baboons. Given the known repertoire of symbols extant during the first dynasty which includes the body of symbols recovered from tomb $\mathrm{U}-\mathrm{j}$, the depiction of any animal, let alone a lion, split in two is unique and highly unusual in this time. We therefore asked what may have prompted early scribes to conceive this imagery and use it to write the words for Beginning, Middle, and End. A key finding in this regard is a symbolic synonym for h $3 t . t$ depicting a baboon which also means "adoration" (Figure 1, bottom). The baboon can be seen on a limestone slab found in the First Dynasty mastaba tomb S3507 in the sarcophagus chamber of Herneith (Figure 5) where it is shown facing the approaching figure of the king of lower Egypt. In the same tomb, couchant lions are depicted in raised relief on the lintel over the sarcophagus chamber (Figure 6) demonstrating the close association between these two animals perceived by these early dynastic tomb designers. In later depictions, the baboon is usually shown facing east, towards the Sun, and was believed to be a manifestation of Thoth. Baboons are well known for their loud morning call ${ }^{2}$ when they issue "contest wahoos" (Fischer et al., 2002: p. 1465).

Edfu's Memphite Creation Myth. It is this behavior which may have inspired an aspect of the Memphite creation myth where baboons personified the seven uttered words $(\underline{d} 3 j s w)$ of Ptah in the act of creating the world and the first seat of the gods on Earth from the waters of the primordial flood (Kurth et al., 2014, pp. 23-26; Chassinat, 2014: pp. 14-15, 18). The seven counterparts of the d $3 j s w$ in the myth are the seven $h n m w$, the potter spirits who shape the words into beings from clay. The western half of the north frieze on the inner girdle wall of the Edfu temple has been translated into German by the Edfu Project (Kurth et al., 2014: p. 322/Émile Chassinat 181, 11) and here, we provide the English translation:

This is a faithful reproduction of the text which Thoth prepared according to the speech of the D3jsw of Mehit-Wrt and which one calls "specification of the places of the first epoch".

This passage clarifies that the text inscribed on the Edfu Temple comes from an older source and identifies the $\underline{d} 3 j s w$ as manifestations of the Great Flood (Mehit-wrt), deified as the great cow who appears as Hathor in the New Kingdom Myth of the Destruction of Mankind also known as the Myth of the Heavenly Cow. In this myth, Hathor is sent to Earth by the vengeful Sun Re to exact his revenge against an irreverent mankind (Guilhou, 2010: p. 2). This destruction forms the pretext from which the world gets reorganized and eventually repopulated during the creative act performed by Ptah which separates Re's dominion in the sky from that of humans on Earth but maintains a bridge between them with the creation of the primordial mound on which Re's Earthly emissary Horus settles and in whose manifestation the Horus kings rule over Egypt.

The key idea we want to convey here is that according to the Edfu texts the seven baboons represented the first seven words of creation as the $\underline{d} 3 j s w$ and the material substance from which these words were made "on the lips of Ptah" so to ${ }^{2}$ For a sample recording see this YouTube video at URL: https://youtu.be/za839cpwUh0. 


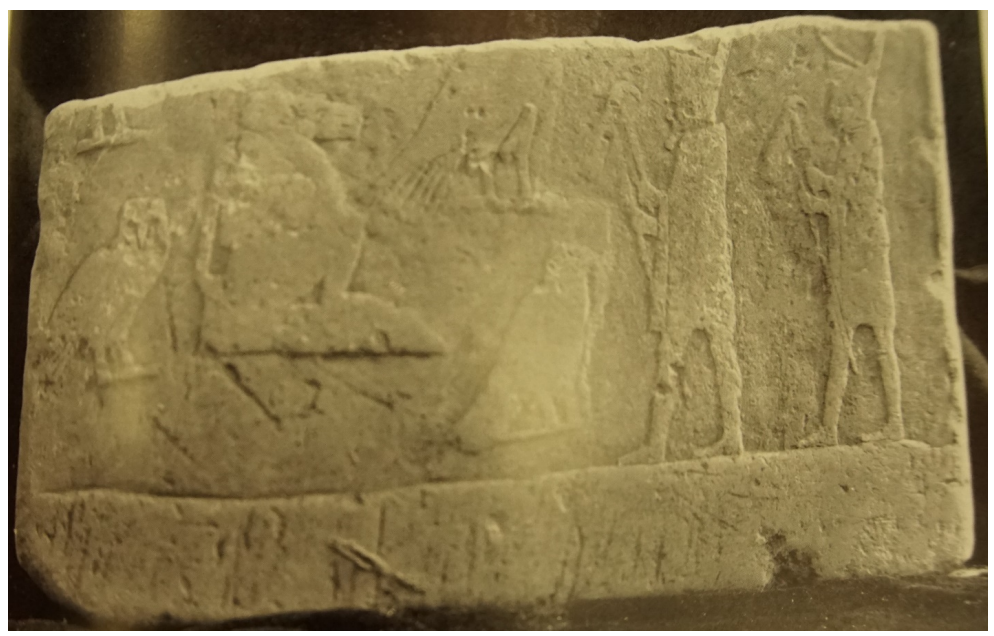

Figure 5. Limestone slab showing a baboon facing approaching king figures from the mastaba tomb of Herneith, S3507 at Saqqara. Photo by M.S. from Emery, 1954, Plate 97.

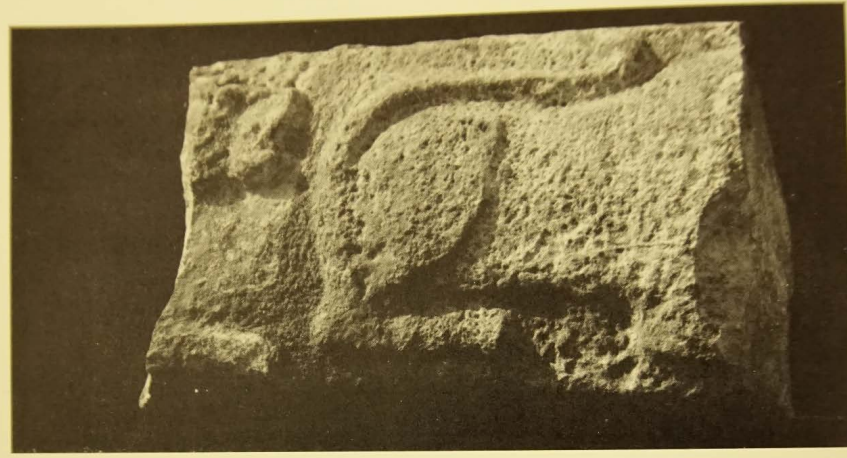

Figure 6. Lintel from the sarcophagus chamber of the mastaba tomb of Herneith, S3507 at Saqqara showing a row of couchant lions. Photo by M.S. from Emery, 1954, Plate 96.

speak was the primordial flood water which drowned the previous rebellion of man against the Sun. This flood was named Mehit, the same name given to the lioness guarding the provisional administrative tent of the first kings of Egypt, which we previously located at Giza (Seyfzadeh et al., 2017). The identical connotational link exists between the five English words sphinx, water, annunciating speech, ritual chisel, and flood, which all can translate into the Egyptian words $h w$ (Vygus, 2015: pp. 2215-2216) and $h w h w$ (Vygus, 2015: p. 2217). From this semantic family, we have previously argued, stems another Egyptian, not Canaanite (contra Selim Hassan) name of the Great Sphinx: Hwrn or Hwrwn/Haurun/Hwrna, etc., as seen on New Kingdom votive steles and the Inventory Stele (Seyfzadeh \& Schoch, 2018: pp. 106-109). This name of the Sphinx, $H w-R n$, can thus be interpreted to refer to a divine utterance of Ptah which became physically manifested as the image of a lion or lioness chiseled from the living rock which emerged from the Great Flood in the same way as the seven words of creation became baboons. 
These seven $\underline{d} 3 j s w$ are individually named and depicted together with the two $\dot{s} b t j w$ (see below) on the upper third register of the western inner girdle wall of the Edfu Temple (Figure 7). Their epithets/names are (from top right): The Hurrying One, The Bull, The Falcon, The Speedy One, The Perfect Front, The Equipped End, The Lord of the Red Ones (Kurth et al., 2014: p. 296). In Figure 8, we show a magnified image of the last three $\underline{d} 3 j s w$ with their epithets/names inscribed in front of their heads; all three are depicted as baboons both in relief and via the context symbol Gardiner E35 (sitting baboon). The Perfect Front (nfr h $3 t$ ) shows the frontal half of an ape or lion, the Equipped End (aprw ph) shows Gardiner F22, and the Lord of the Red Ones ( $n b d \dot{s} r w$ ) is an allusion to the blood-tinged faces of feasting lions as well as the appeased wrathful Hathor in the Myth of the Destruction of Mankind, who drinks red-colored beer and falls asleep taking a rest from her mission of completely destroying humankind (for the various meanings of $d \dot{s} r w$ see Vygus, 2015: p. 280).

Of help in this regard are also utterances by the seven $\underline{d} 3 j s w$ inscribed on the opposite side of the temple into the inner face of the eastern wall at the third register. There, the seventh and last $\underline{d} 3 j s w M n q b^{3}$ is quoted as saying (Kurth et al., 2014: p. 583/Émile Chassinat 322, 13; our English translation from German):

We have provided the House of Life in/with glorifying words. [htm.n pr ' $\mathrm{nh} \mathrm{m}$ $d \dot{s} r w]$

The House of Life was a later Egyptian word for library, initially representing the palatial subterranean hall where life-provisions were given to the king and his closest associates (Helck, 1987: p. 236). This interpretation that the House of Life was also a library is justified because the sixth $\underline{d} 3 j s w$ Baq-baq whose pronouncement immediately precedes that of $M n q b$, refers to the "Book House" $p r$ $m \underline{d} 3 t$.

Kurth et al.'s interpretation of $d \dot{S} r w$ as "glorifying words" is based on a context they believe is developed by the pronouncements of the fourth through sixth $\underline{d} 3 j s w$ 's referring to praising words ( $b 3 w$, see footnote 4 in Kurth et al.'s citation above). A closer look at these pronouncements of the last four of the seven $\underline{d} 3 j s w$ inscribed on this side of the temple however reveals that the first two deal with how the gods are being exalted, i.e. with written words of praise $(b 3 w)$, while the last two deal with where this occurs (Kurth et al., 2014: pp. 582-583/Émile Chassinat $322,8-13)$. We therefore reason that $m d \dot{s} r w$ was not meant to refer to the written words of praise and glory themselves, but their location. If $d \dot{s} r w$ in both these passages of the Edfu Texts was in fact meant to allude to lions, then while the prepositional phrase $m d \dot{s} r w$ here was meant to be literally read as "in the red ones", it was actually meant to be understood as "in the lions". Evidence that this could be the intended meaning of $m d \dot{s} r w$ is that $b 3 w$ can also mean leopards (b3: leopard; Vygus, 2015: p. 331), an allusion to the leopard hide worn by the $s m$ priests and Seshat, the patron goddess of libraries in ancient Egypt ${ }^{4}$. In other ${ }^{3}$ Here presumably his name, not his epithet.

${ }^{4}$ The dotted skin of leopards was reminiscent of the starry sky where the souls were believed to dwell. 


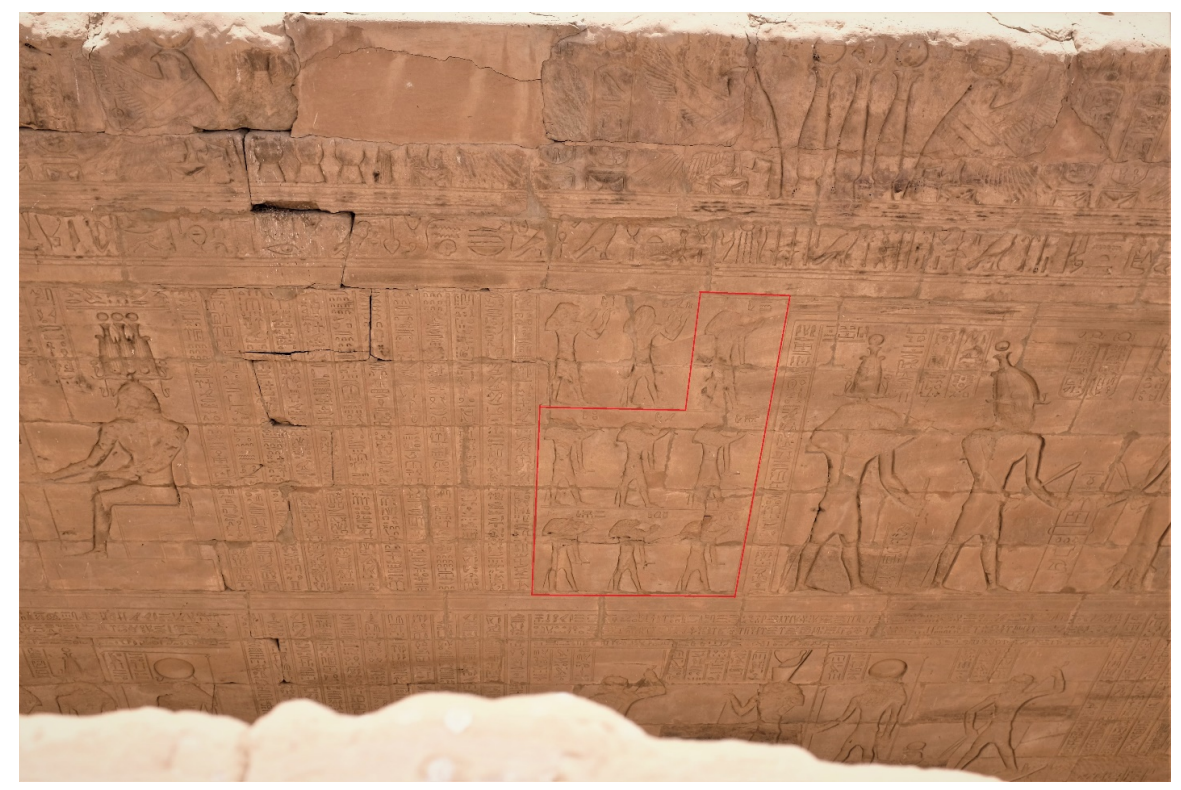

Figure 7. The seven $\underline{d} 3 j s w$ (red frame) and the two šbtjw. The former are the seven personified words of creation in the Memphite creation story and are manifested as baboons. Their names are written in front of their heads. From the inner western girdle wall of the Edfu Temple. Photo by R.M.S., May 2019; modified.

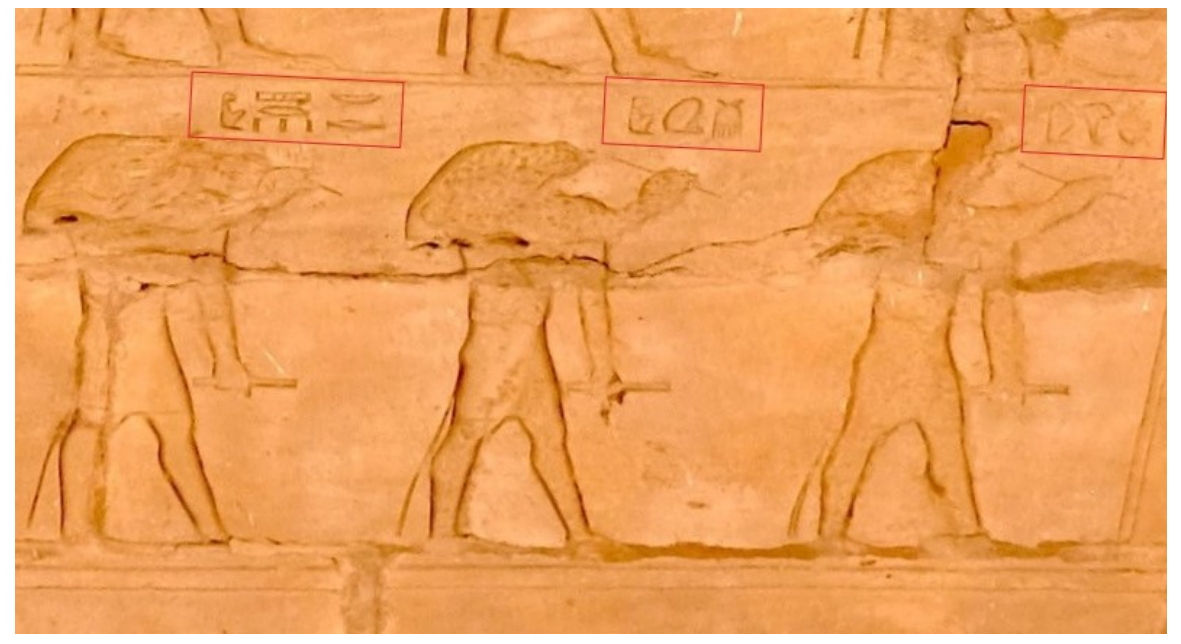

Figure 8. The three of seven personified creation words $(\underline{d} 3 j s w)$ associated with the split lion iconography with their hieroglyphic epithets/names framed in red (from right to left): Nfr h $3 t . t$ The Perfect Front, 3prw ph The Equipped End, and $N b d \dot{s} r w$ The Lord of the Red Ones. Photo by R.M.S., May 2019; modified.

words, the $\underline{d} 3 j s w$ quoted in this passage of the Edfu texts appear to invoke the prehistoric shaman magician and the early historic patron of writing Seshat with $b 3 w$ and lions with $d \dot{s} r w$ using Heka, the magical language of phonetically activating magical formulas using speech which appears to mean something different or more mundane. At a deeper level of intended meaning therefore, it is possible that in these last four pronouncements of the seven $\underline{d} 3 j s w$ magicians and scribes were incidentally being called into existence in order to operate in- 
side libraries to be guarded by, or exist within, red lions.

Evidence of this association between "red" and a subterranean location is the fact that the "Red House" pr dis $r$ was the royal treasury in the cellar of the first known palace in the north at Buto ( $P$ Hr msn established by Horus Djer) where the House of Life was later also situated (by the time of Horus Den) all being part of the pr nswt, the king's private, and presumably cooler and more secure, basement sanctuary within the palace pr ' 3 (Helck, 1987: p. 228). Some of the recessed walls of the subterranean burial chambers of Horus Djer and Horus Djet, for example, were also pained in red (Petrie, 1901: p. 8). Another association between "red", "writing", the double lion Aker who guards the entry and exit of the netherworld ( $d w 3 t)$, lions, and the Great Sphinx is the library patron goddess Seshat-associated title called Director of the Rwt Women (rwt = gateway, $r w t j$ is a later synonym for the double-lion Aker), a title possibly referring to the facility where red paint was produced (Helck, 1987: p. 264) and used, for example, to color reliefs, to write on papyrus, and to paint the Great Sphinx's face and possibly the entire body.

When Giovanni Battista Caviglia (1770-1845) cleared the area between the paws of the Great Sphinx in his 1816-1819 excavation campaign, he discovered a small temple with three steles by Thutmose IV (i.e. the Dream Stele) and Ramses II, a small lion statue, fragments of lion statues and a sphinx, and beard and uraeus fragments which had fallen off the Sphinx. All of these, including the temple wall, were painted in red (Hassan, 1949: p. 11). In addition, even the masonry blocks used to repair the monument were apparently stained in red, an unusual treatment in ancient Egypt's monuments (Mariette, 1857: p. 95). ${ }^{5}$ This cumulative evidence establishes the necessary context for the idea that $d \dot{s} r w$ is an allusion or epithet which was meant to refer to lions and that the $\underline{d} 3 j s w$ Lord of the Red Ones ( $n b d \dot{s} r w$ ) was their master. There is even the possibility of a word play alluding to a lion split in half by a fissure. When separated into two words, $d \dot{s} r w$ becomes a subordinated clause with an active participle predicate literally translating to "he who/that which separates the lion" (Vygus, 2015: pp. 282, 393). Then, htm.n pr 'nh $m d \dot{\grave{s}} r w$ should be understood as "we have provided the House of Life in that which separates the lion", i.e. the space which splits the lion, like, for example, the major fissure through the Great Sphinx (see below in this section) at the bottom of which Auguste Mariette in fact discovered a chamber (see Discussion Re: "Hall of Records").

Evidently, ancient Egyptian theologians viewed the iconography of a split lion not only as part of the exclusive linguistic set of symbols used to describe the story of Egypt's creation after its destruction by an epic flood instigated by the Sun, but part of the very first seven words of the recreation of the world after this epic disaster. To underscore the significance of this choice, the correspond${ }^{5}$ Quote from Mariette in its original French: Les fouilles ont montré que tous les blocs de la maçonnerie avec laquelle le corps de l'animal symbolique a été façonné, sont enduits d'un badigeon rouge pâle, de peu de consistence et tel qu'on n'en trouve jamais sur les monuments égyptiens de la bonne époque. 
ing analogy in the Abrahamic religious creation story might be considered to be the creations by God in the first seven days, i.e. light, the sky, the Earth and plants, the heavenly bodies, birds and fish, animals and humans, and rest.

We conclude that the concept of the split lion found its way both into the recording of economic transactions and theological myth, two different cultural aspects of a civilized people who used symbols to write, i.e. record language. The question we therefore asked is from where the notion of a split lion came and how this notion was able to so profoundly influence such diverse expressions of Egyptian culture.

Major Fissure through the Great Sphinx. The American Research Center in Egypt (A.R.C.E.) conducted a survey of the Sphinx and its temples (The Sphinx Project) from 1979 to 1983. This involved establishing and orienting a grid and using photogrammetry to measure elevations down to individual rock layers. Among the findings was the stratigraphic definition of an easily observable feature: A wide, >2-meter gap traversing the caudal portion of the Great Sphinx down to the ditch and extending both northwest and southeast across to the north and south enclosure walls and onto the causeway of the pyramid of Khafre (Figure 9; Lehner, 1991, 1992: p. 12). This composite geological defect composed of a series of converging fissures is most pronounced in the middle member of the Mokattam Formation, also known as Member II, but extends through the lower Member I (Lehner, 1991: p. 203). The gap in the back of the Sphinx, officially explored in late 1853 by Auguste Mariette though likely helped by much earlier accounts and unpublished excavation reports, is still visible on an early photo taken during the 1926-1935 excavations by Émile Baraize (Figure 10), but was soon cemented over by his restoration team (Lehner, 1991: p. 48). The traces of the fissure are still visible today both across the monument, the ditch, and the enclosure (Figures 11-14). This fissure extends to a depth of at least 5 meters into the bedrock of the ditch and enclosure wall (Lehner, 1991: p. 159); the weak zone through which the fissure runs most likely existed before the monument was carved from the rock, and at some point after the initial monument was carved, the fissure opened and/or eroded out. A possible hint of it is noticeable on a New Kingdom stele found near the Sphinx (Hassan, 1953: p. 71) dedicated to Thutmose III, at a time when the monument had not yet been excavated and restored by his grandson Thutmose IV (Figure 15). It is possible that the fissure was meant to be depicted on this stele, but it could also be an accidental scratch on the stele. The symbolic fan of $\dot{S} w$, the air (or $\dot{s} w t$, the shadow), seems to be inserted into the same place on the back of the Sphinx where the fissure is located.

As is typical in Egyptian relief, the fan is in the same plane as the profile of the Sphinx but could also possibly be imitating the actual physical widening of the fissure as it courses into a deeper plane behind the Sphinx from this perspective and expands into a fan-shaped crevice as it traverses the ditch and enclosure wall on the north (Figure 14). Lehner found ancient cultural deposits (e.g. pottery shards) in this crevice (Lehner, 1991: p. 158-159) and speculated that the entire 


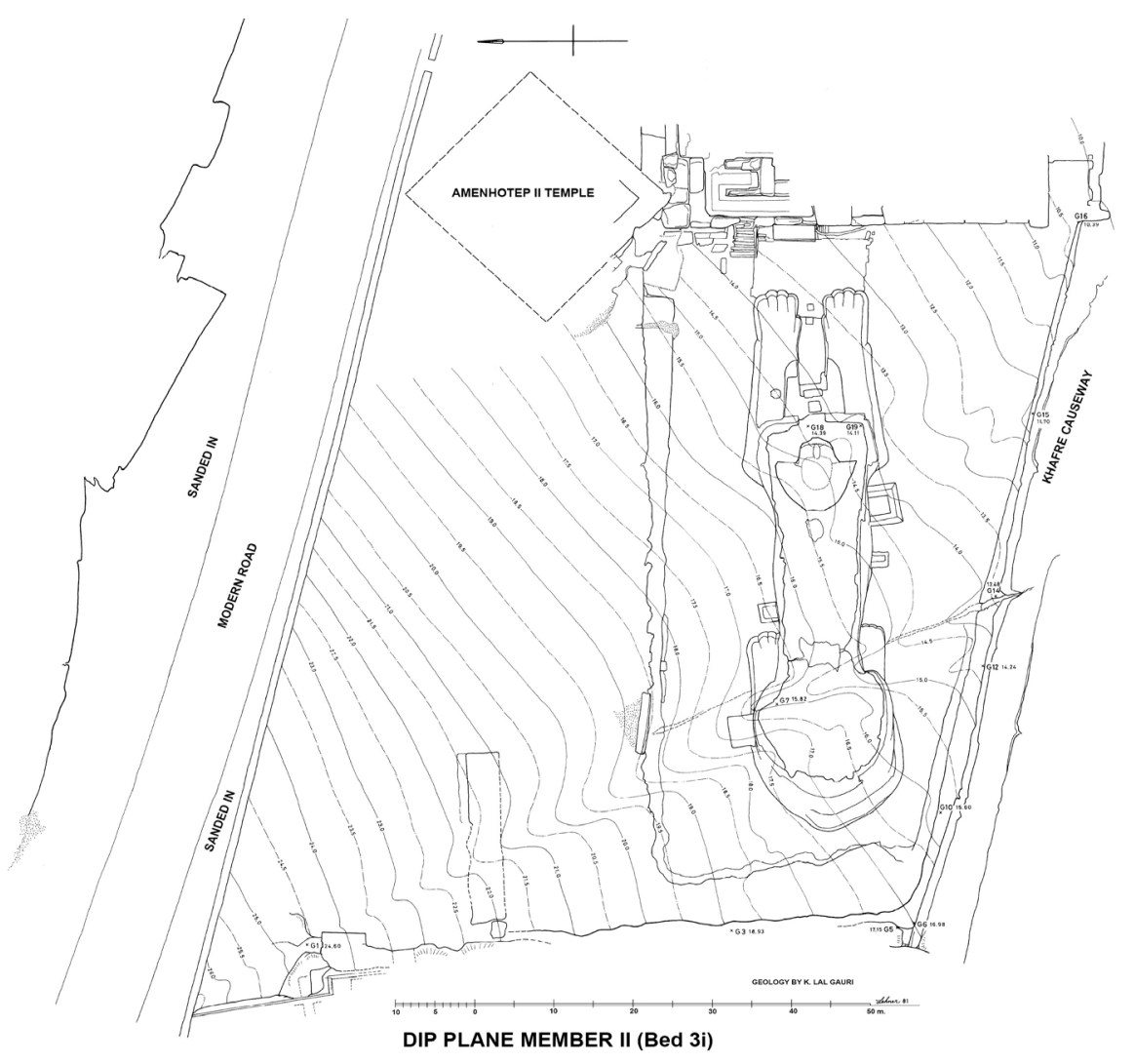

Figure 9. Middle Member of the Mokattam Formation, elevations in 0.5-meter segments showing the position of the major fissure through the body of the Sphinx, the ditch and the enclosure walls relative to the contour of the limestone's layered sediment as it slopes down from northwest (lower left) to southeast (upper right). The fissure coincides with the contour shift. Drawing courtesy of Mark Lehner. "Drawing d-sa-005 from Egypt/Giza/Khafre Causeway”. (2017) In ARCE Sphinx Project 1979-1983 Archive. Mark Lehner, Megan Flowers, Rebekah Miracle (Eds.). Released: 2017-12-23. Open Context. <http://opencontext.org/media/52204672-a08a-4ef1-915c-558689809227> ARK (Archive): https://n2t.net/ark:/28722/k29s2043b.

fissure explains why the builders had to unnaturally extend the body of the Sphinx relative to the size of the head (Lehner, 1991: p. 409) suggesting the fissure existed before the creation of the monument. This would be a way to account for the disproportionately small head relative to the body of the Great Sphinx; an alternative view is that the current head on the Sphinx is not the original head (the original, subsequently weathered, head was re-carved and thus is too small for the body; see West and Schoch in NBC, 1993; Schoch \& Bauval, 2017; Seyfzadeh et al., 2017). The most important piece of evidence presented by Lehner, however, is his observation that the interior of the fissure walls inside the body of the Sphinx appear worked, i.e. squared, suggesting ancient repair attempts (Lehner, 1991: p. 203).

\section{Discussion}

In summary, we have identified a significant cultural role for three symbols which date to the earliest phase of writing in ancient Egypt: The frontal and 


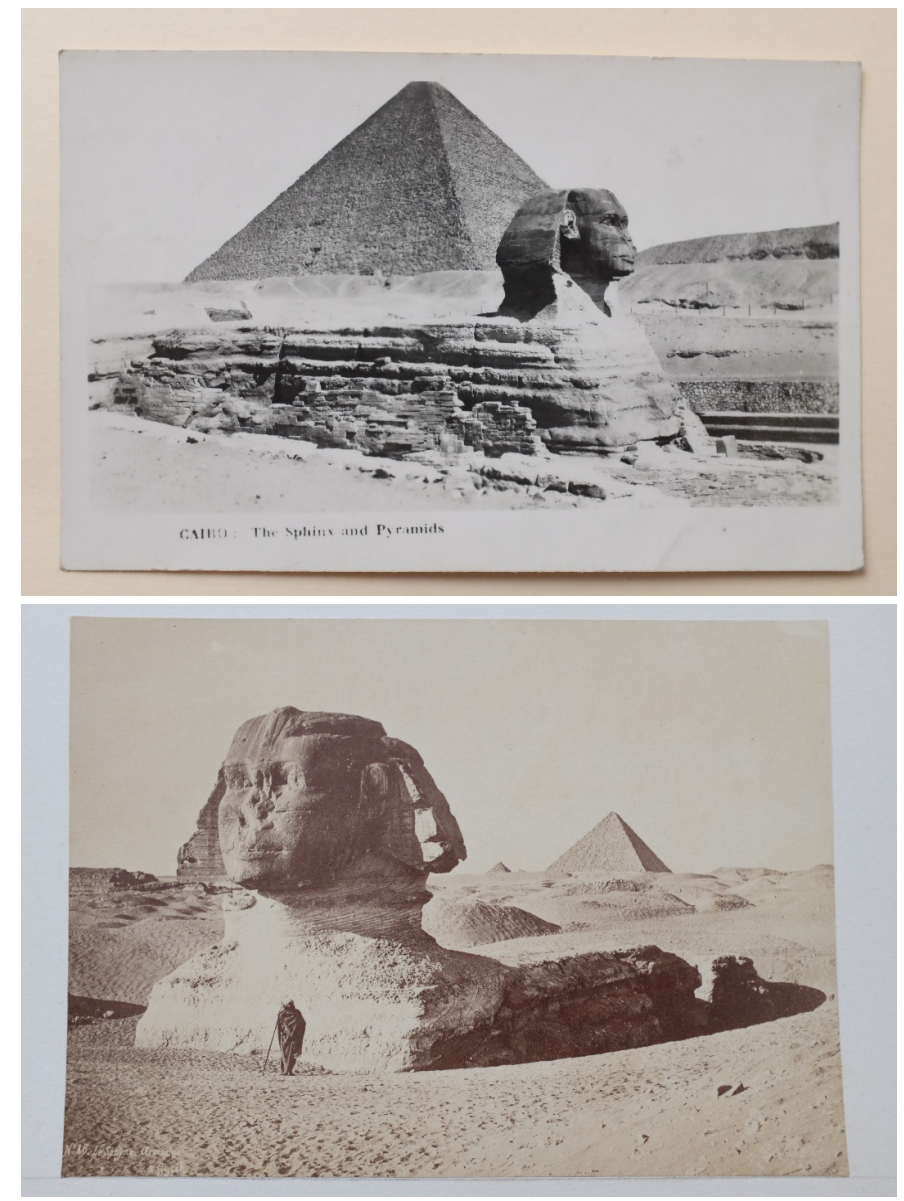

Figure 10. South looking north (top) and northeast looking southwest (bottom) views of the Great Sphinx taken before and during the early phase of Émile Baraize's excavation campaign (1926-1935). The major fissure through the waist as shown in these two photographs is still open before repairs during which it was cemented over. (Top Photo: A postcard published by N. and G. Chrissanthou, Alexandria and Cairo, circa late 1920s or early 1930s. Bottom Photo: Photograph circa 1880 attributed to Pascal Sébah (1823-1886; see Woodward, 2003, for a discussion of the Sébah family business). Postcard and photograph from the collection of Robert Schoch).

caudal lion symbols and a split or crack-like image likely representing the dividing line between these two halves. These symbols prominently appear in proto-dynastic and early dynastic labels used to designate the quality of oil. The frontal and caudal lion halves also feature prominently in the Memphite creation myth recorded on the inner western wall of the Edfu Temple. One way to explain the creation of these unusual symbols is that their prehistoric inventors witnessed a physical monument in the shape of a lion split into two halves by a fissure, such as is seen in the core body, ditch, and enclosure of the Great Sphinx at Giza. The sight of this awe-inspiring lion(ess) could explain why the iconography pervaded diverse aspects of Egyptian culture such as economic record-keeping and theology. 


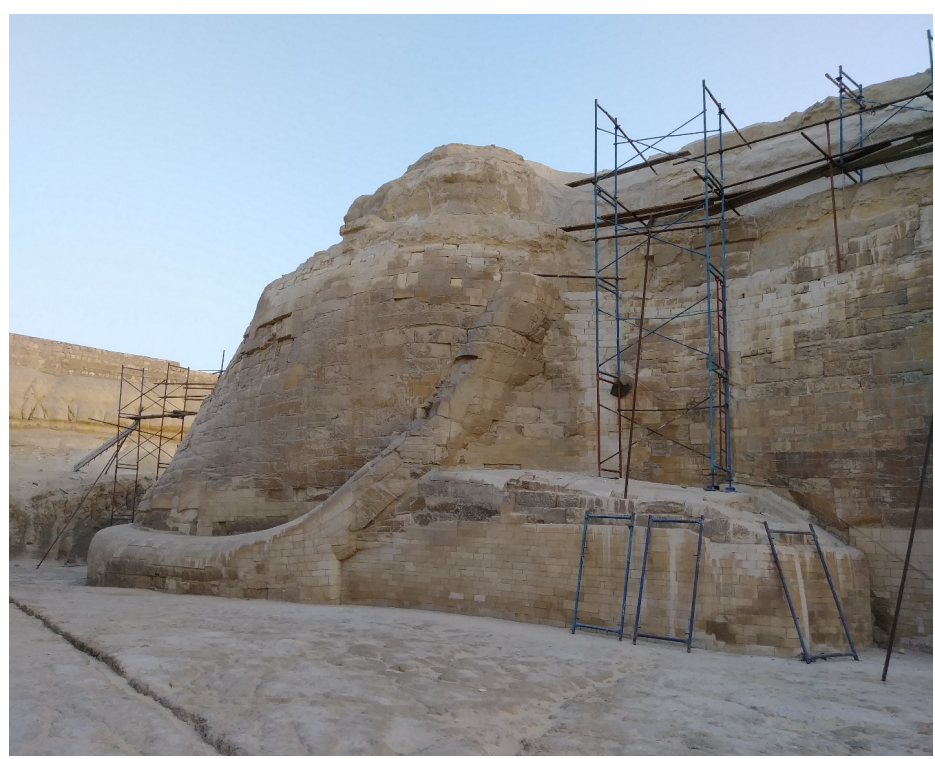

Figure 11. The repaired major fissure on the south side of the Great Sphinx's waist can be seen to course through the hind paw and on through the ditch. Photo by M.S., June 2019.

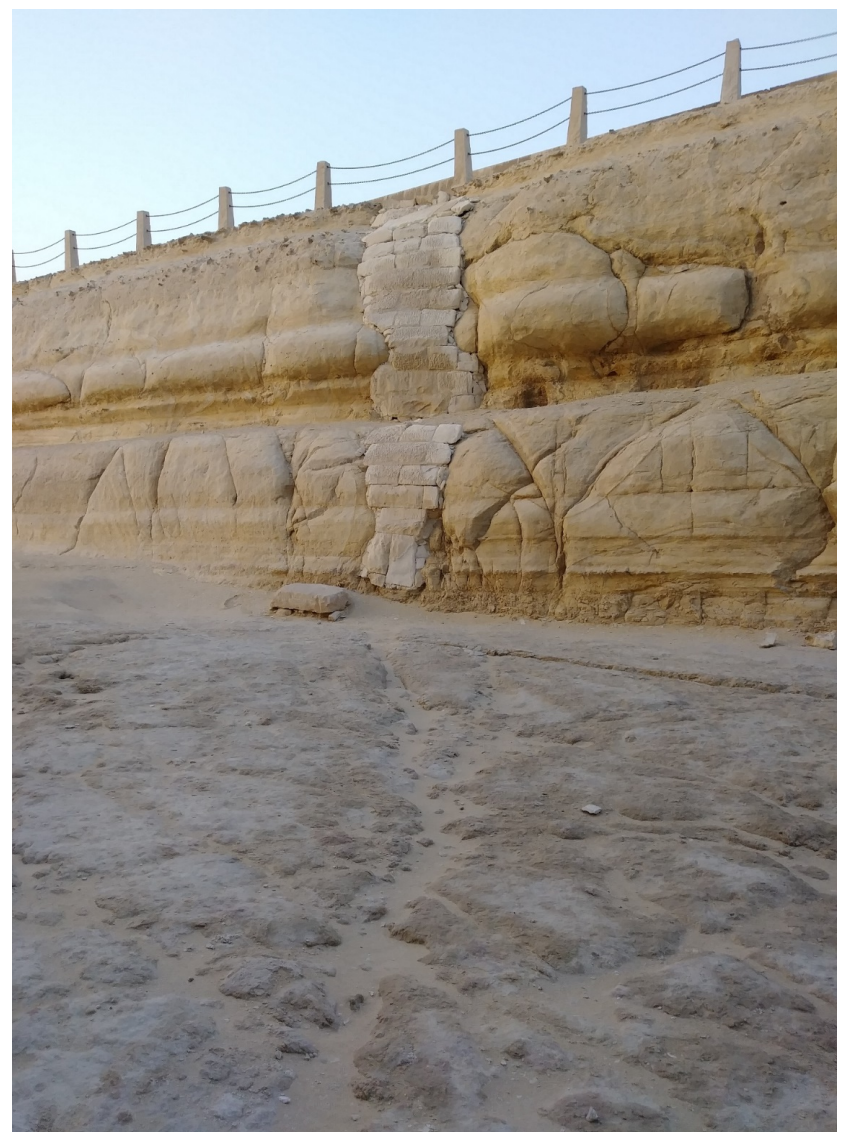

Figure 12. The southern extent of the major fissure through the enclosure wall viewed from the northwest along its course through the ditch floor. Modern masonry repairs have covered the fissure. Photo by M.S., June 2019. 


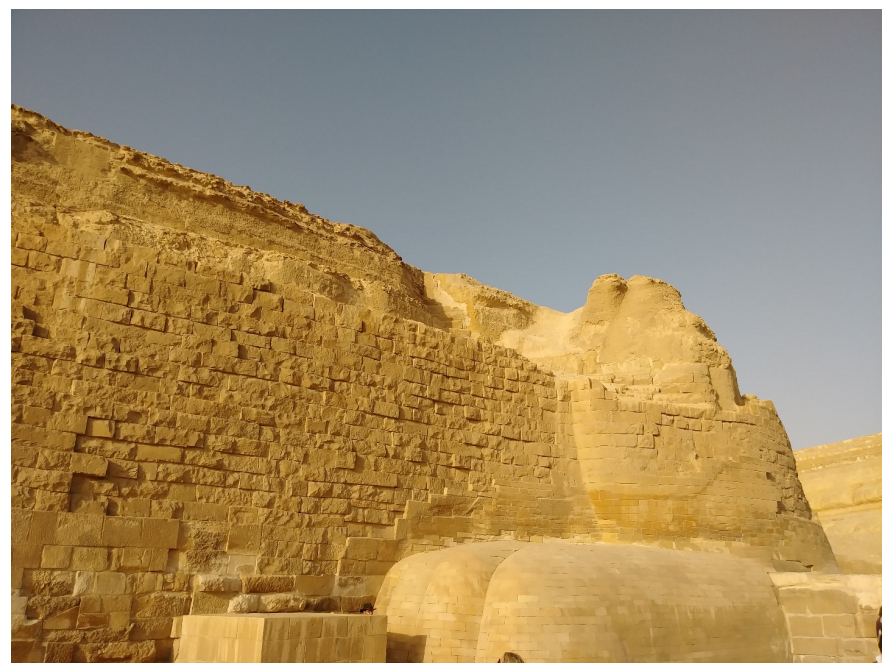

Figure 13. The repaired (beginning with Baraize, circa 1926) major fissure through the left waist of the Sphinx as seen from the north. Photo by M.S., June 2019.

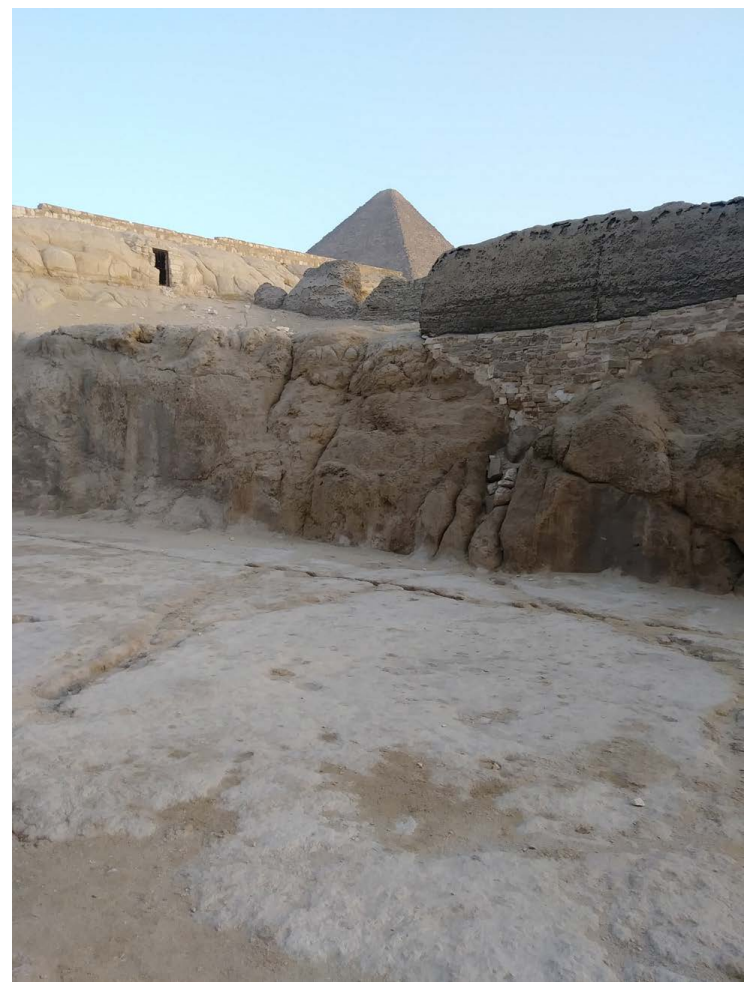

Figure 14. The northern extent of the fissure coursing through the ditch and enclosure wall as it broadens into a fan-shaped wider crevice. Photo by M.S., June 2019.

Dating the Origin of the Creation Myth. While the economic use of these symbols evidently pre-dates the Old Kingdom and the time of Khafre, the formulation of the creation myth before this time needs further evidence. Even though the Edfu texts were inscribed during Egypt's Ptolemaic dynasty, they 


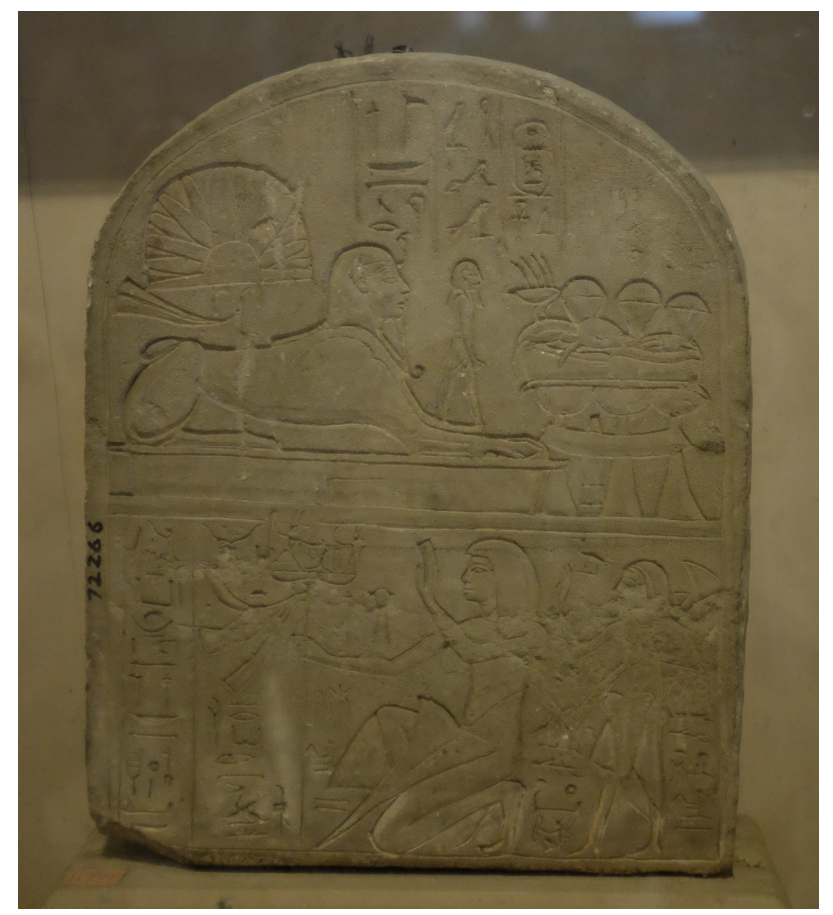

Figure 15. Stela Number 7, dedicated to Thutmose III, paying a royal visit to the Great Sphinx, probably while hunting in the area. A light-colored line appears to course through the waist of the Sphinx seemingly imitating the major fissure though an accidental scratch cannot be ruled out. Into the defect is inserted the fan $\dot{S} w t$, the shadow or divine spirit as if personifying the fissure through the Sphinx and crevice on the north side of the enclosure (Figure 14). Cairo Museum; photo by R.M.S., June 2019; modified.

probably stem from earlier documents, since several passages in the texts state that this is so. But how old could these original source texts be? The Myth of Horus narrated on the second register of the inner walls of the Edfu Temple for example, features an epic victory of good versus evil in the killing scene where Horus the Son of Isis impales Seth in the form of a red Hippopotamus (Fairman, 1935: p. 27). The concept of such an encounter can be traced back to pre-historic Hierakonpolis, where the figurines of a falcon and a hippopotamus were found buried together inside a post-hole as a foundation deposit in the southeast corner of a pillared hall (structure 7) in the elite cemetery HK-6 (Droux \& Friedman, 2007: pp. 7-9). This structures dates to the mid- $4^{\text {th }}$ Millennium B.C.E. The southeast corner hints that the two contenders were imagined dwelling in that area of the horizon where Sirius, Venus, and Mercury at times hover (Krauss, 1997: pp. 233-234; 235-238).

Further evidence of a much older date of the creation myth may be detected in the architecture of the Osireion at Abydos. The Osireion is a still enigmatic temple featuring a central island surrounded by a deep moat onto which two sets of steps emerge. The center of the island features two four-cornered depressions 
and two rows of five granite pillars with four more sandstone pilasters ostensibly completing two rows of seven columns or supports on which granite blocks were placed (Figure 16 and Figure 17). The moat is surrounded by two sets of eight cells with one central cell on the eastern side (Figure 16). The temple is commonly interpreted to be a symbolic tomb of Osiris who was intensely worshipped in this area since at least the Old Kingdom in his identity of the Foremost of the Westerners (hntj jmntjw). The Osireion is tentatively dated to the reign of Seti I (second king, $19^{\text {th }}$ Dynasty, circa 1290-1279 B.C.E.), whose votive temple is immediately west and whose temenos wall surrounds the Osireion. The most compelling piece of evidence dating at least the Osireion's sandstone enclosure walls of the temple to Seti I is a granite dovetail stone block connector bearing his cartouche found in situ embedded into the masonry of the northwest corner by Henri Frankfort (Hamilton, 2018: pp. 62-65). The central island made of sandstone, with its granite pillars on top, physically connects to the enclosure wall by thrust beams of the same type of sandstone thus creating a speculative temporal link between it and the placement of this dovetail in the $19^{\text {th }}$ Dynasty (Hamilton, 2018: p. 80). The temple foundation's depth, on the other hand, the source of the water of the moat, and the rate of the rising water level over time alongside the Nile leave doubt about when the island and moat were originally made even if the enclosure may be dated to the New Kingdom.

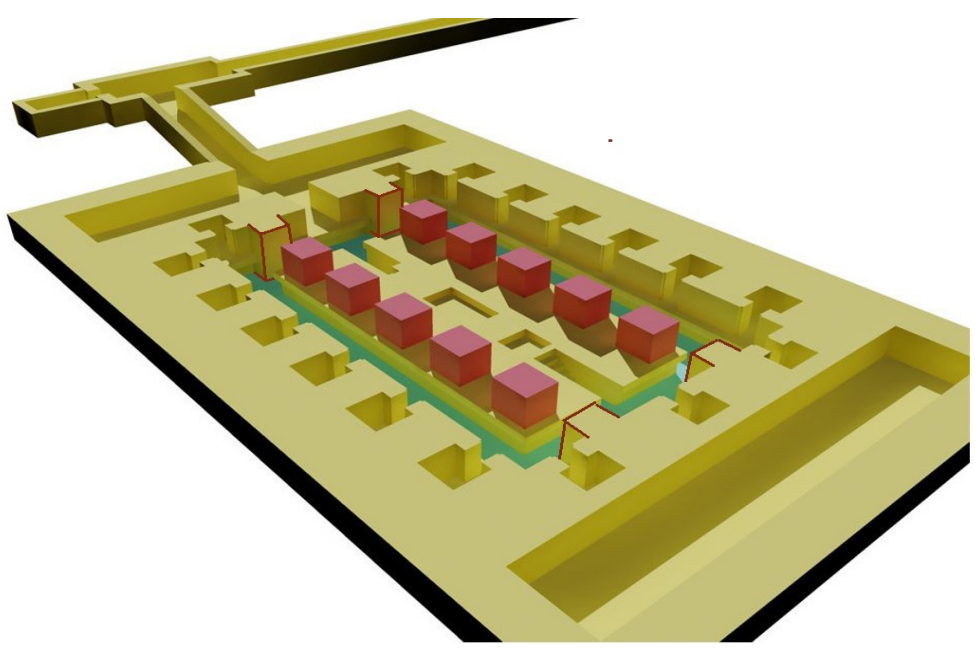

Figure 16. Graphic reconstruction of the Osireion looking west from the east corner of the Central Hall. At the top are shown the entrance corridor onto whose interior west and east walls are inscribed the Book of Gates and the Book of Caves, respectively. From Murray's Hall the sloping passage leads into the main temple, through the First Transversal Hall (Hamilton, 2018). The temple walls are made from hewn blocks of sandstone and limestone. On the central island, granite pillars are highlighted in coral color. The water-filled surrounding moat is featured in blue. The sandstone pilasters/piers are framed in coral to indicate that they may have been part of an architectural design theme inspired by the seven $\underline{d} 3 j s w$ and $h n m w$ in the creation story of the Memphite Theology (see Discussion). Graphic design courtesy of Keith Hamilton; modified with permission. 

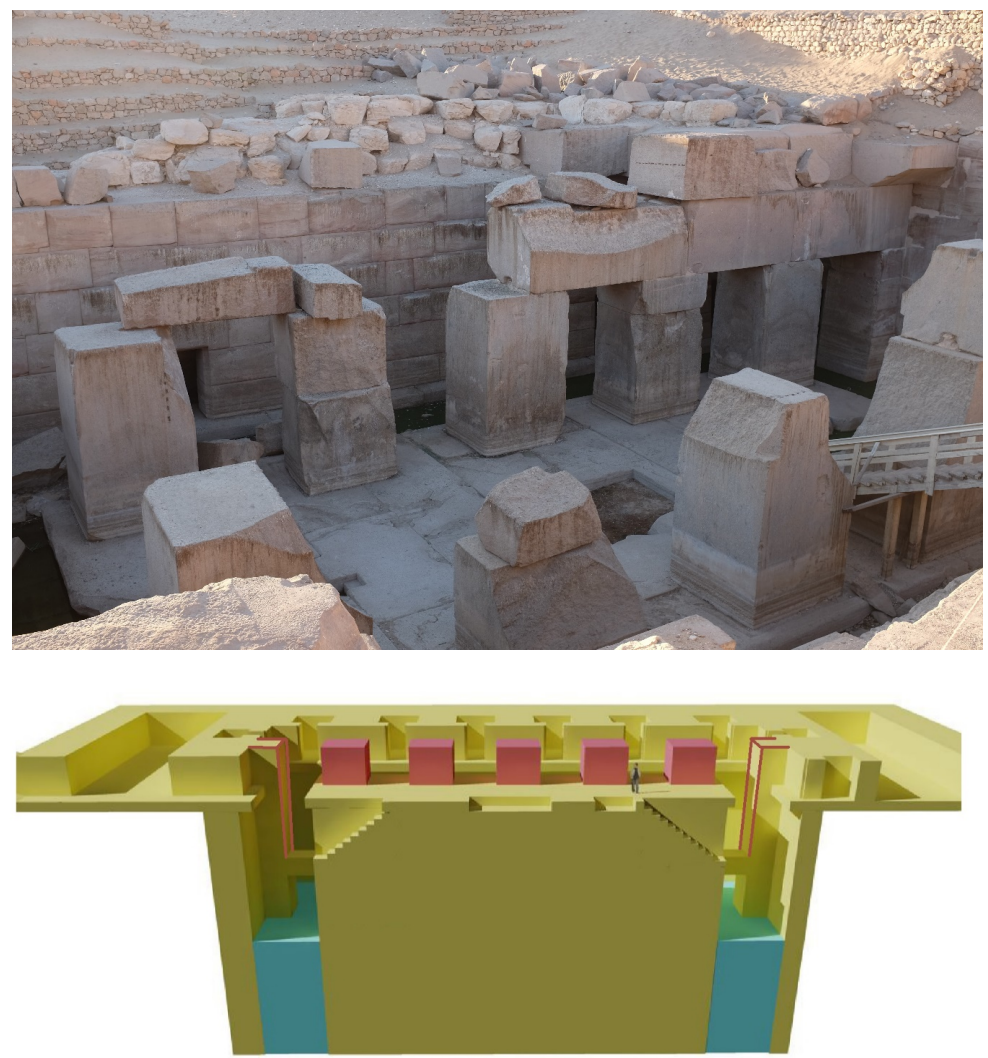

Figure 17. Top: Osireion, approximate south view looking north. Bottom: Graphic simulation of a vertical axial view of the Osireion as seen from the southeast looking northwest. This view gives a sense of the depth of the temple foundation including the observed (east) and predicted (west) horizontal thrust beams anchoring the temple walls to the island, and visualizes the stairs leading from the moat onto the island platform with its two quadrangular depressions possibly representing the two śstjw, w3j/ The Far and ' 3 / The Great (see Discussion). The northwest row of granite pillars is highlighted in coral color and the sandstone pilasters/piers (outlined in coral) adjacent to these complete an apparent set of seven total pillars. Photo by R.M.S., June 2019; graphic design courtesy of Keith Hamilton; modified with permission.

We would like to propose a new interpretation of the idea behind the design of the Osireion: The two sets of seven pillars on the north and south side of the temple represent, respectively, the seven $\underline{d} 3 j s w$ and the seven hnmw of the Edfu creation story symbolically having emerged from the waters of the moat representing Mehit-wrt the Great Flood on the steps to the island in the moment of utterance. The Perfect Front and The Equipped End could then be represented by the sandstone pilasters on the northeast and northwest sides. The two depressions on the island would represent "The Far" (w3j) and "The Great" ( 3 ), i.e. the two $\dot{s} b t j w$, who personified the two concepts of a distant creative thought by Ptah and this idea then brought into focus during the act of conceiving the world (Kurth et al., 2014: pp. 312, 323/Émile Chassinat 177, 7-9; 181, 13-16). In the creation story written on the frieze of the western inner girdle wall of Edfu, the $\dot{s} b t j w$ weave the net of reeds into which Horus lands to establish the seat of Re's 
representative on Earth (Kurth et al., 2014: p. 23/Émile Chassinat 14, 14-15, 1; translated by us into English from German):

The Land is still pervaded by the primordial sea when his majesty reaches the Far and the Great at the place of creation and the first reeds emerge from it at that place where the two gods tie the reeds in the flood waters so that the wing of the circling one can visualize. When Horus arrives, he is carried by the Nebit Reeds and thus comes into existence Edfu and the seat of the throne of Horus.

The Osireion can thus be viewed as a megalithic, concrete representation of the conversion of divine creative thinking, i.e. the act of conceiving a distant idea and bringing it forward into focus by catching it with a woven net, into uttered words and the conversion of these words, in turn, into the substance of the world, stone in this case resting on a firm foundation, the primordial mound. In the Memphite creation story, this mound is personified by Tatennen and is represented, we propose, by the central island of the Osireion, floating in the middle of the primeval flood waters represented by the water in the moat. The seventeen cells surrounding the central island and moat could represent the Ogdoad and the Ennead $(8+9)$, the two pantheons of the Hermopolitean and Heliopolitean cosmogony of ancient Egyptian theology governed by Thoth and $R e$, respectively. The architecture of this temple, therefore, appears to symbolically express the elements of the Edfu creation story thus dating it to at least the New Kingdom and maybe much earlier depending on the still debated provenance of the Osireion's foundation and granite pillars.

Conspicuously, the quasi-square Sphinx Temple, like the Osireion, has fourteen pillars in its central court divided into two rows of six bridged on each north and south side by a central pillar on the north-south axis of the temple (Figure 18). Ricke points out that ancient plundering of the Sphinx Temple, its unfinished state, and the complete lack of evidence of a priestly Sphinx cult in any of Giza's tombs make possible a wide range of interpretations of the meaning of the Great Sphinx and Sphinx Temple (Ricke, 1970: p. 32). Here, we would like to offer a variant opinion. Khufu's eldest son Kawab carried the priestly title of "Arm of $D w 3 w$ " (see tomb of Meresankh III), the personified day-gate (i.e. "Today") of $A k e r^{6}$, the double-headed lion above which the $d w 3 t$ extends. This suggests to us, that a Sphinx-related cult in fact existed during the time of Khufu, before Khafre, and hints of it have simply been missed due to the prevailing opinion then and now that the Sphinx was made by Khafre, in part prompted by an only partially preserved, ambiguous line of text on the Dream Stele (Ricke, 1970: p 32; see also discussion in Schoch \& Bauval, 2017). In other words, the east-facing Sphinx, or a lion or lioness sculpture before it was re-carved, was "Today" and a hypothetical counterpart was the personified night-gate Yester$\operatorname{day}(s f)$.

${ }^{6} \mathrm{We}$ consider a possible alternative explanation that the two heads of Aker represented the Morning and Evening Star based on Rolf Krauss's astronomical analysis of the Pyramid Texts that $n t r d w 3 w / j$ or $s b 3 d w 3 w / j$ referred to Venus in its east and west horizontal manifestations (Krauss, 1997: pp. 216-234). 


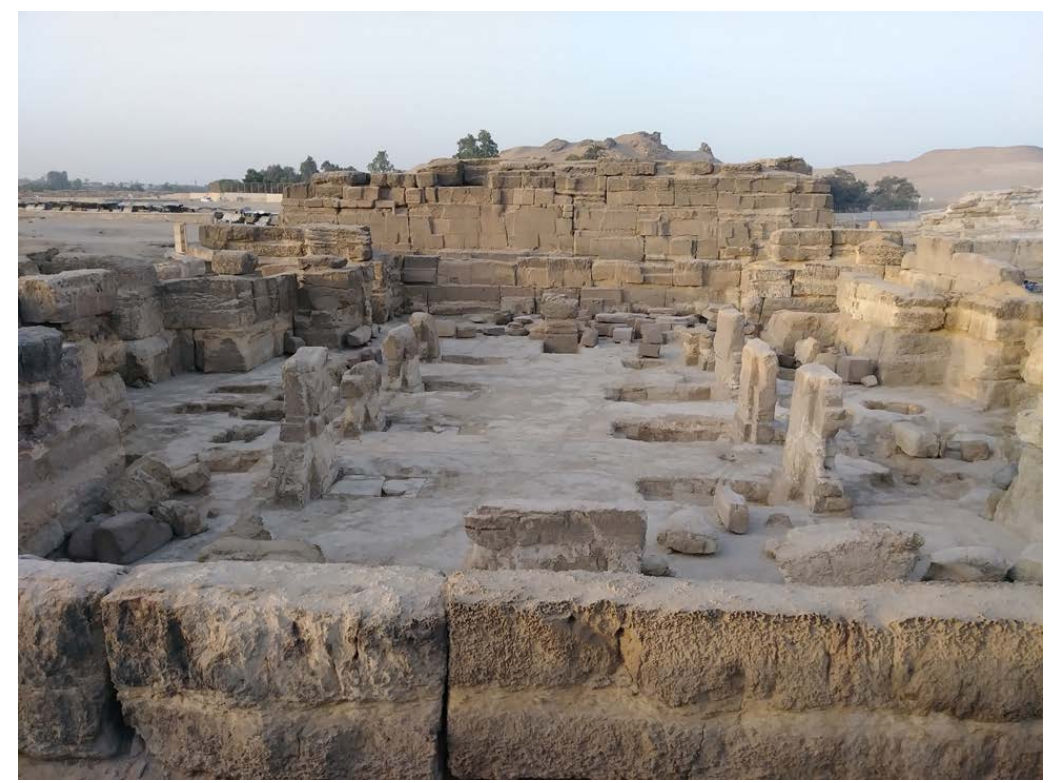

Figure 18. North view of the Sphinx Temple looking south along the central north-south axis with the tops of the three north-side pillars seen head-on in the front. Photo by M.S., June 2019.

Ricke interprets the bilateral symmetry of the temple along the east-west axis as evidence that it was meant to monumentalize the path of the Sun in its transient manifestation as Kheprj at sunrise in the east, Re at noon in the south, and Atum at sunset in the west. Thus, the Sphinx Temple was meant to monumentalize the Sun cult and the 24 square pillars $(4 \times 6)$ lining the perimeter of the court to be that of the 24 hours of the day and night symbolically dividing the circular path of the Sun around the world, and the two pairs of remaining pillars, east and west of this perimeter symbolized the arms and legs of $N u t$, the night sky (Ricke, 1970: p. 36).

With respect to the central court, Ricke speculates that since there was not enough room, only ten emplacements for statues were made next to pillars, five west and five east. He observes that the statues were of different heights. To make up for the two-statue short-fall from twelve, the two terminal emplacements on the north-south temple axis were supposedly made larger to hold a broader statue which may have represented two entities (Ricke, 1970: pp. 37-38). We think this is the weakest aspect of Ricke's interpretation. The central court has fourteen pillars, as does the Osireion when its sandstone pilasters are included, and ten statue emplacements matching the number of granite pillars (i.e. ten) of these fourteen. At the north end, a water channel feeds a basin, possibly a symbol of the watery origin of what the pillars represent. We take the number of fourteen pillars at face value and think that they represent the seven $\underline{d} 3 j s w$ and the seven hnmw which would explain why each pillar had a different height, since each of these fourteen creative forces of nature was uniquely named. Thus, the central court of the Sphinx Temple fulfilled the same function as the central island of the Osireion, where three of ten granite pillars were made from two 
pieces and the four pilasters were made from sandstone instead of granite (Hamilton, 2018: pp. 54, 57): It was the symbolic place of the origin of the world made from the unique creation words and their material manifestations in attendance. The primordial watery substance from which they were made, the Great Flood, was represented by Mehit, the lioness monument adjacent to the Sphinx Temple in our model, later remodeled into the Great Sphinx. Is there any evidence to support this theory?

When viewed from the south, for example from the roof of the Valley Temple, the Great Sphinx might have appeared to look over three pillars seen head-on from this perspective (Figure 19). This imagery symbolically is again reminiscent of the three lion-related $\underline{d} 3 j s w$ and such an iconographic image was found by Petrie in the tomb of Horus Djer at Abydos carved into an ebony-wood tablet (Petrie, 1901, Pl. Va, Number 13; Figure 20). This wooden tablet shows an unusually elongated, couchant lion, possibly split into frontal and caudal halves, next to a square enclosure within which a row of three baboons are sitting. Judging by their heads and faces, Petrie's contention that these are captives is less likely.

The presence of baboons on this tablet is yet another piece of evidence that the early dynastic Egyptians viewed the lion monument, which we think already then existed at Giza, as a mythical being associated with creation and the great flood. In this context, the burial of seven young lions in the northeast most of Horus Aha's (Mena) subsidiary graves at B16 in Umm El-Qa'ab, further supports the significance of lions and the number seven in the earliest phase of

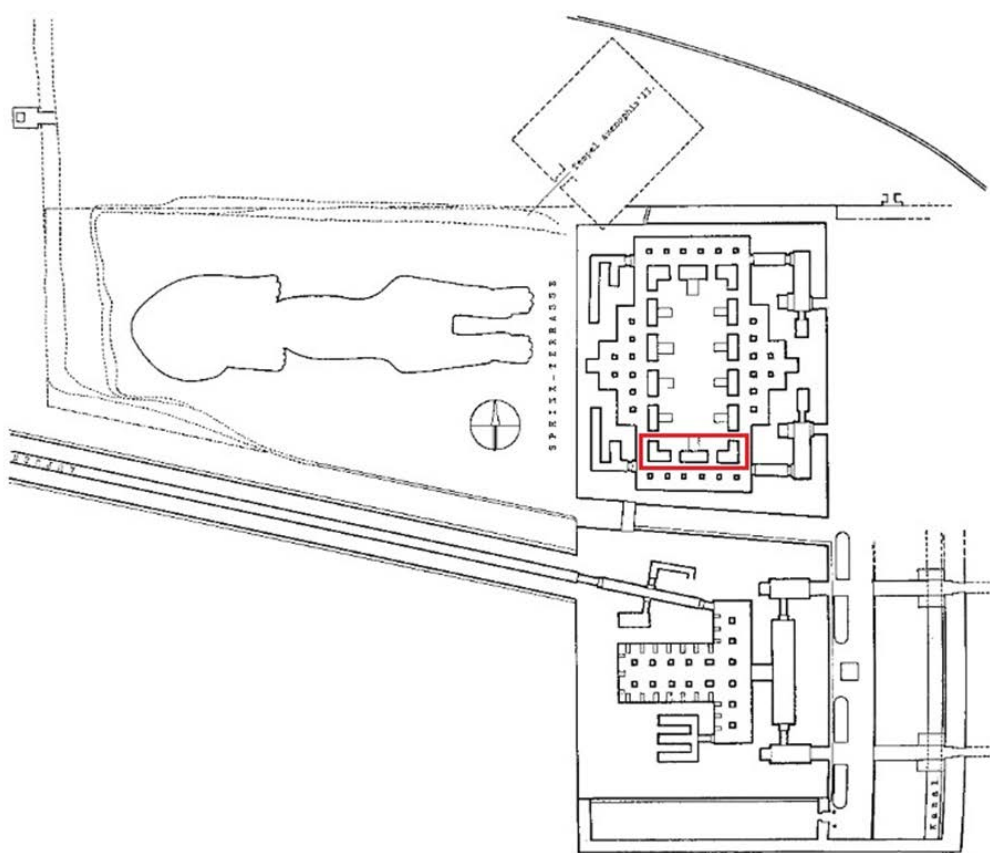

Figure 19. The Sphinx complex and Valley Temple viewed along the south-to-north axis highlighting the three southernmost pillars inside the court of the Sphinx Temple. Drawing based on Ricke, 1970: p. 5; modified. 


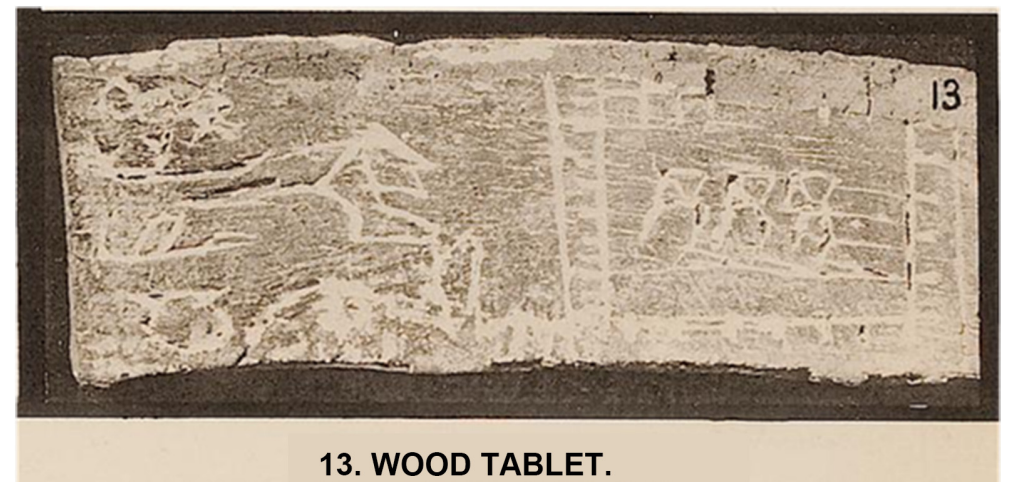

Figure 20. Ebony tablet from the tomb of Horus Djer discovered by Petrie showing an elongated couchant lion, possibly in two halves, and a rectangular structure with three baboon-like animals sitting in profile. Photo by M.S. from Petrie, 1901, Plate Va, Number 13.

dynastic Egypt (Bestock, 2009: p. 29). Archeological proof of a physical association between baboons and the Great Sphinx temple complex comes from Uvo Hölscher's excavation in front of the Valley Temple. There, apparently fallen to the ground of its south entry (the Hathor gate), he found a colossal statue of an ape made from black granite, which once towered above this portal from a recessed east-facing niche high above the entry likely matched by another like it in a similar niche over the north entry, also known as the Baset Gate (Hölscher et al., 1912: p. 42). Both entrées were probably flanked by pairs of likewise colossal Sphinxes again demonstrating the close association between baboons and lions (Hölscher et al., 1912: p. 15; Blatt VIII).

The Fissure. What might have caused this fissure and the elevation contour shift of the rock layers sloping down traversing the area of the Great Sphinx? One possibility is a seismic event which might explain the contour shift of the sedimentary rock thereby weakening it and leading to gap formation. Another possibility is mentioned in the Inventory Stele which tells the story of how Khufu inspected the Sphinx and repaired it while examining a nearby Sycamore tree damaged by lightning (Seyfzadeh \& Schoch, 2018). Might this same event have damaged the Sphinx by blowing off its nemes tail and cracking open the waist, ditch, and enclosure? The Giza Plateau near the pyramid of Khafre and to its east shows several areas of vitrification including grooves and crevices with a vitrified lining and interior (Schoch, 2016; Catherine Ulissey, Robert Schoch, and Mohamed Ibrahim, personal observations). In the Osiris shaft's second level, there are possibly vitrified veins of reddish-to-black rock extending an estimated ten meters or more deep into the limestone (Robert Schoch and Catherine Ulissey, personal observations). The overall pattern of this ostensible rock melting and glass formation appears to run in a west-to-east (or east-to-west) orientation from pyramid to Sphinx suggesting that this was a single impact event of extremely high heat (tens of thousands of degrees) such as could be modelled with a solar plasma beam powerful enough to be able to pierce the Earth's electro- 
magnetic shield and strike the surface of Earth and also penetrate deeply beneath.

No such event, i.e. a Super Solar Proton Event (Super SPE), Coronal Mass Ejection, or some other form of a major solar outburst, is known to have occurred on Earth in the last 10,000 years. However, radioactive atmospheric isotope data $\left({ }^{14} \mathrm{C}\right.$ and $\left.{ }^{10} \mathrm{Be}\right)$, corresponding temperature patterns, atmospheric ionization proxies, contemporary megafauna extinctions, contemporary petroglyphs found around the world imitating the hypothetical shapes of such massive ion strikes (van der Sluijs \& Peratt, 2010: pp. 39-41) through the atmosphere ${ }^{7}$, and mythical lore, such as the Egyptian Myth of the Destruction of Mankind telling the story of a vengeful Sun on a mission to punish mankind, hint that such violent solar storms of various intensity may have hit Earth at the beginning (circa $10900-10800$ B.C.E.) and end (circa 9700 B.C.E.) of the Younger Dryas (LaViolette, 2011: pp. 305, 309; Schoch, 2012: pp. 87-92, 173-179), as well as repeatedly during this period, culminating in world-wide ocean level rises and epic flooding just as told by the many ancient flood myths of the world.

In order to test this theory, we propose that rock samples should be obtained from the interior of the major fissure within the body of the Sphinx and its extensions across the ditch and enclosure, as well as the Osiris Shaft and the various apparently vitrified surface features higher up towards the pyramid of Khafre, and geologically tested for evidence of such vitrification. According to Lehner, the interior surfaces of the fissure in the Sphinx's body did not appear weathered and were possibly worked (thus removing any earlier weathering), but the examination was hampered by repair debris from Émile Baraize's restoration (Lehner, 1991: pp. 48, 203).

Male or Female Lion Monument. Previously, we proposed that the first kings of Egypt, operated a scribing facility and archive at Giza protected by a monumental lioness called Mehit/The Northern One (Seyfzadeh et al., 2017). The evidence for this comes from a sealing associated with Horus Djer where the facility is marked with the st $3 w$ symbol (suggesting Ro-st $3 w$, i.e. Mouth of Caves, a.k.a. the Giza plateau) and the fact that the scribes' names associated with this facility are written in the now-lost pictographic script of Buto indicating that they came from the north. Furthermore, the same sealing contains the symbol for north and the lioness Mehit is facing in the direction of the symbol for east hinting at its equinoctial orientation. The bent-rod symbol in the back of the lioness unequivocally identifies her in an inscription dated to the later Fourth Dynasty high official of Khufu, Wepemnefret, where she is mentioned by name on his mastaba's slab stele and her gender appears unequivocally female both in the depiction and because her name ends with the letter for the sound " $t$ ", the usual form of female gender identification in Semitic languages. The tandem title "The King's Chief Librarian (Scribe) and Guardian of the Royal Archives of Mehit' is topographically grouped on the stele with a priestly title associated with a

${ }^{7} \sim 125$ times as powerful as the 1956 Solar Proton Event based on ${ }^{14} \mathrm{C}$ atmospheric generation (LaViolette, 2011: p. 310). 
royal library under the patronage of Seshat, Egypt's goddess of writing and astronomy first mentioned during the reign of Horus Djer on the Palermo Stone segment of the Royal Annals of Ancient Egypt. We therefore concluded that the prehistoric monument from which the Great Sphinx was later made was already a 7000- to 8000-year old weathered lioness when an Old Kingdom ruler first laid hands on it. It is possible that weathering had obscured the head and neck features leading to ambivalent gender identification by various observers.

The evidence we present in this paper suggests that the lion's frontal half shown in at least some of the oil and wooden tags we propose to have been inspired by a stony lion monument at Giza may be that of a male lion is at odds with our previous proposal that the monument represented the female Mehit. However, the phonetic value of this symbol was in fact female, i.e. h3t.t (Front/Oil), the precious initial, therefore front fraction, fluid pressed from the substrate fruit. In other words, while the carvings of the lion's front into ivory and wood, at times in the extant record from the First Dynasty, may appear male, the word encoded by it was definitively female ${ }^{8}$. We therefore think that the observed apparent gender variability may either be a case of observer variation due to the weathered state of the monument or some of the scribes active in the oil trade took liberties and depicted what they originally recognized as a female monument with a male symbol. On some First Dynasty sealings evidently depicting the known female lioness Mehit identified by the bent rods above her back, for example, a male lion mane can nevertheless be seen demonstrating this occasional liberty taken by some scribes (Kaplony, 1963, \#145, 146, 163).

Association between Lioness and Writing. The Mehit-guarded administrative facility sealed luxury goods destined for both royal and elite private tombs in the first half of the First Dynasty (Helck, 1987: p. 186) presumably to administer tributes from the northern territory of the Delta after unification. By the time of Horus Den, a permanent palace bureau $(h w t)$ had been established at PHrw Msn/Seat of the Harpooning Horus ${ }^{9}$ for these scribes and the provisional satellite facility was no longer used (Helck, 1987: p. 213, 4.). Nevertheless, Mehit remained their patron (Figure 21).

At least two more such administrative satellite facilities identified by distinct sealings were initially in operation immediately after unification by Horus Narmer, "Animal Rows + Trap" (Figure 22, right pane) and "Dual Royal Banner", both of which soon disappeared from the record (Helck, 1987: p. 179). The animal trap symbol sht (ensnare, trap, hunt; Gardiner T26; Figure 22, left pane) is similar in shape to the depiction of the Mehit-guarded facility which appears as an animal-surmounted building with a door and chambers, conventionally referred to as $\operatorname{Pr} w r /$ The Great House/Great Hunter Hall (Figure 23). This ${ }^{8}$ For comparison, on some tags the symbol looks female (e.g. http://xoomer.virgilio.it/francescoraf/hesyra/labels/xxqaa16.htm and http://xoomer.virgilio.it/francescoraf/hesyra/labels/xxdjer1.htm) and in others it looks male (e.g. http://xoomer.virgilio.it/francescoraf/hesyra/labels/xxaha1.htm and http://xoomer.virgilio.it/francescoraf/hesyra/labels/xxnarmer1.htm).

${ }^{9}$ This palace had previously been established in Buto by Horus Djer (Helck, 1987: p. 152). 


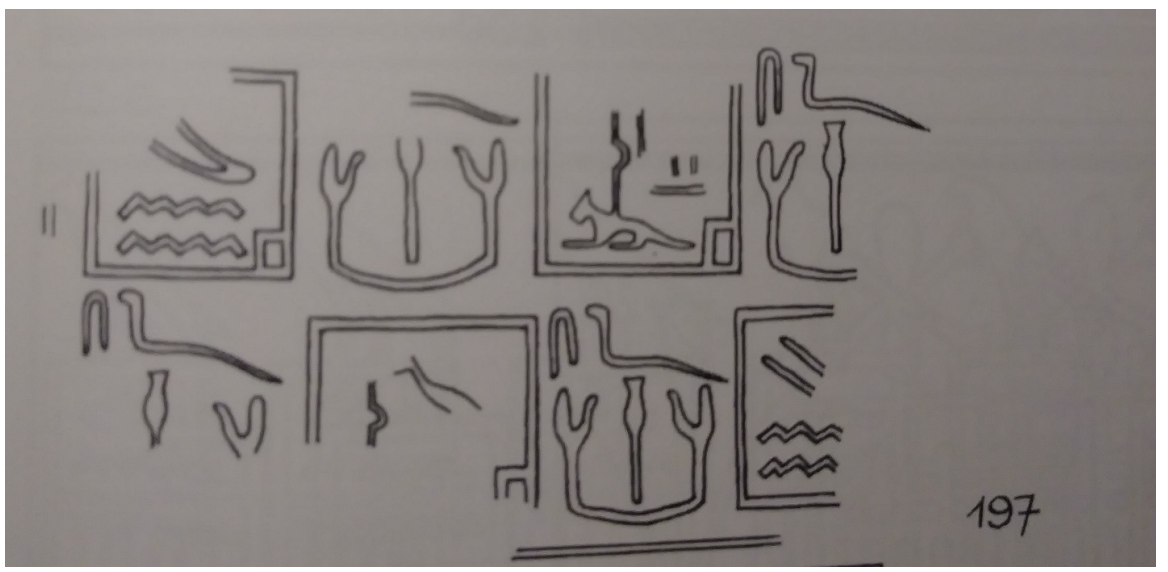

Figure 21. Seal impression of $S d k 3$ during the reign of Horus Den originating from the newly established scribe's bureau at the Seat of the Harpooning Horus in Buto, the northern palace of the Thinite kings. Mehit, now established as the scribes' patron goddess, is shown within a $h w t$, i.e. inside a walled facility presumably in the palace basement. Photo by M.S. from Kaplony, 1963, Tafel 53, Image 197.

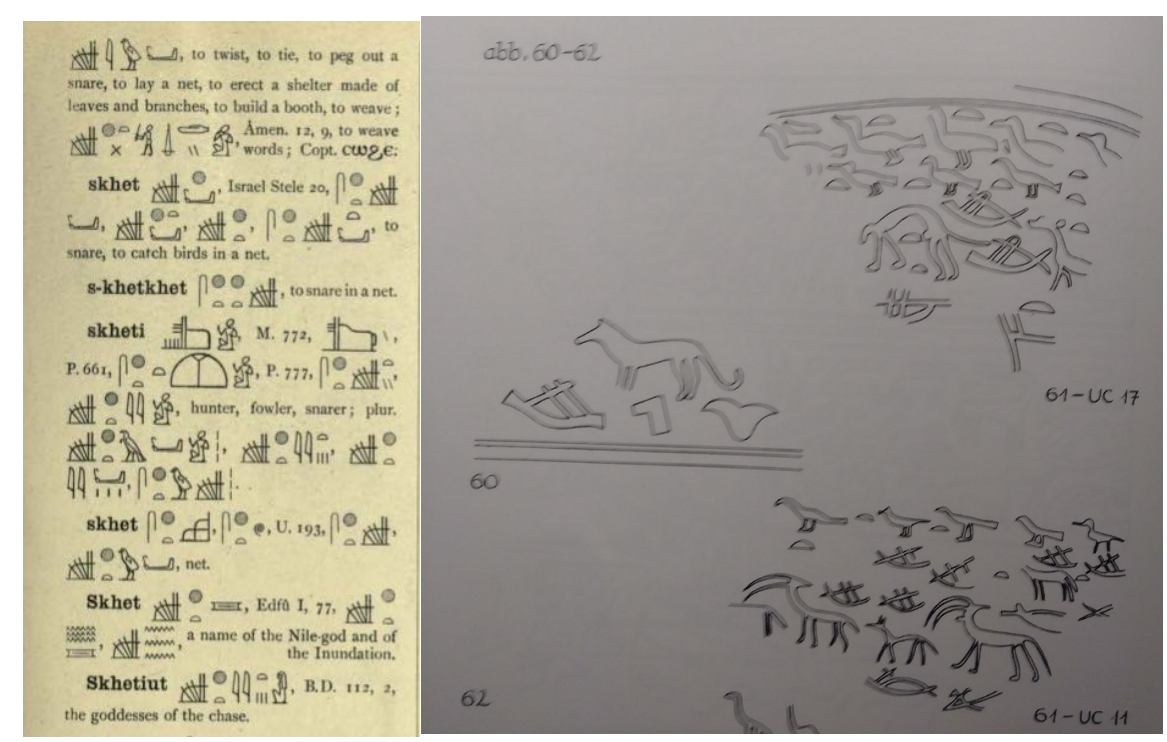

Figure 22. Left pane shows Gardiner T26 with phonetic and logographic value of sht: snare, trap, catch, hunt. From Budge, 1978: p. 695a. Right pane shows a selection of sealings from the Animal Row + Trap dynastic state satellite facility. Photo by M.S. from Kaplony, 1963, Tafel 26, Images 60 and 61.

building depiction is one of the oldest icons used as a symbol in writing in ancient Egypt dating back to pre-dynastic Scorpion I's tomb U-j and possibly depicts a central structure at the large prehistoric settlement of Hierakonpolis/Nekhen ${ }^{10}$. Invariably, this building is shown on these nine ivory labels with a couchant animal, in one case closely resembling the shape of a lion (Dreyer, 1998, Tafel/Plate 30, \#61-69).

${ }^{10} \mathrm{HK} 29$ a. See URL:

https://www.hierakonpolis-online.org/index.php/explore-the-predynastic-settlement/hk29-the-cere monial-center. 


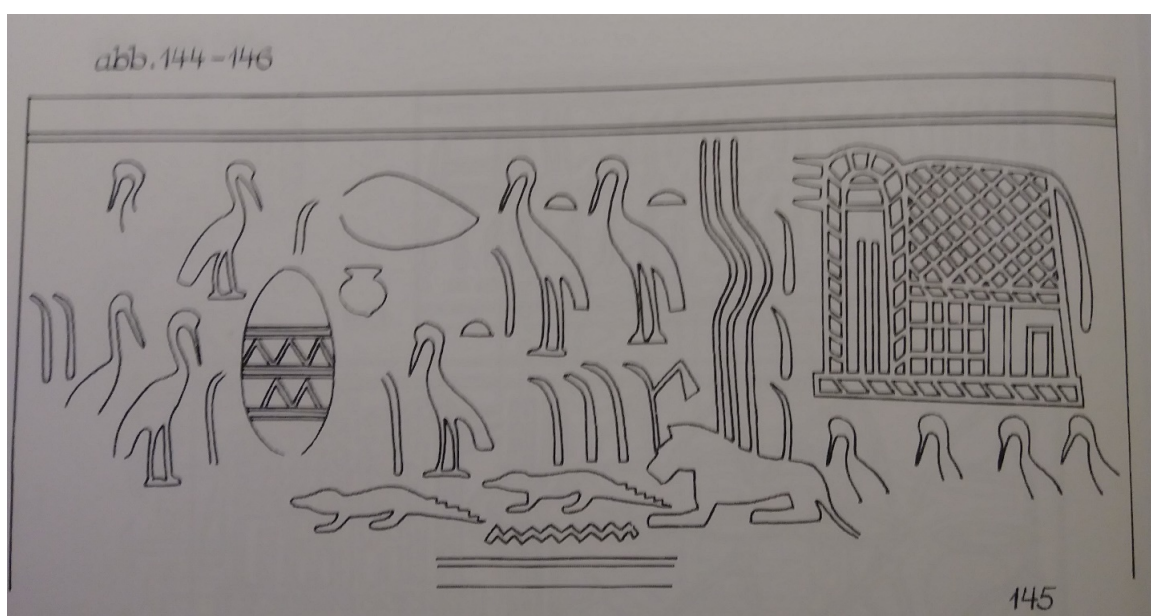

Figure 23. Mehit-sealing showing the Great Hall Pr wr in detail. Photo by M.S. from Kaplony, 1963, Tafel 42, Image, 145.

On the inner wall of the Edfu Temple, a monumental stone-scroll in the form of a girdle wall surrounds the temple proper. Into it the Egyptian Horus Myth is inscribed, and the netting and catching of birds, animals, and humans is a prominent theme (Figure 24). The Memphite creation story also recorded there on the western frieze describes how the two $\dot{s} b t j w$ tie the first reeds emerging from the waters of the Great Flood into a secure foundation onto which Horus can descend to establish his throne on Earth, in other words the foundation of the mythical Edfu Temple sitting on the original mound of creation. The image of a falcon landing on a nest of woven reeds is not far removed from the hunting and catching of birds with a net made from papyrus stalks.

A common context between woven flax to make textiles and rope for nets and traps, and woven papyrus stalks to make papyrus sheets for writing is also demonstrated in mastaba S3035 of the First Dynasty's high official Hemaka under Horus Den, who had these materials protected in specially-made wooden boxes and had them all stored in the same chamber, magazine room $\mathrm{Z}$ located behind the east wall of the niched tomb (Emery, 1938: pp. 41, 43-44).

From the large cache of animal bones found near the ceremonial center HK29a at Hierakonpolis (Friedman, 1996), it becomes clear that centuries before Horus Narmer and the beginning of dynastic Egypt (circa 3000 B.C.E.), prehistoric sedentary Upper Egyptians hunted wild animals not for immediate killing and consumption, but to keep them alive in captivity and slaughter them later ritually (Hendrickx et al., 2010: p. 21) ${ }^{11}$. Animals were also ritually sacrificed and buried as retainers around elite tombs (e.g. tomb 47 in cemetery HK6) and there is at least one example of a shaman-like dwarf burial (tomb 50) surrounded by baboons, a leopard, an aurochs, an ostrich, and a crocodile ${ }^{12}$. The role of the later

\footnotetext{
${ }^{11}$ See also Stan Hendrickx, 2012, lecture. Sunday at the Met: The Dawn of Egyptian Art. URL (time-cued): https://youtu.be/2G4C1SkPBWs?t=470.

${ }^{12}$ Hierakonpolis Online. URL:

http://www.hierakonpolis-online.org/index.php/explore-the-predynastic-cemeteries/hk6-elite-ceme tery.
} 


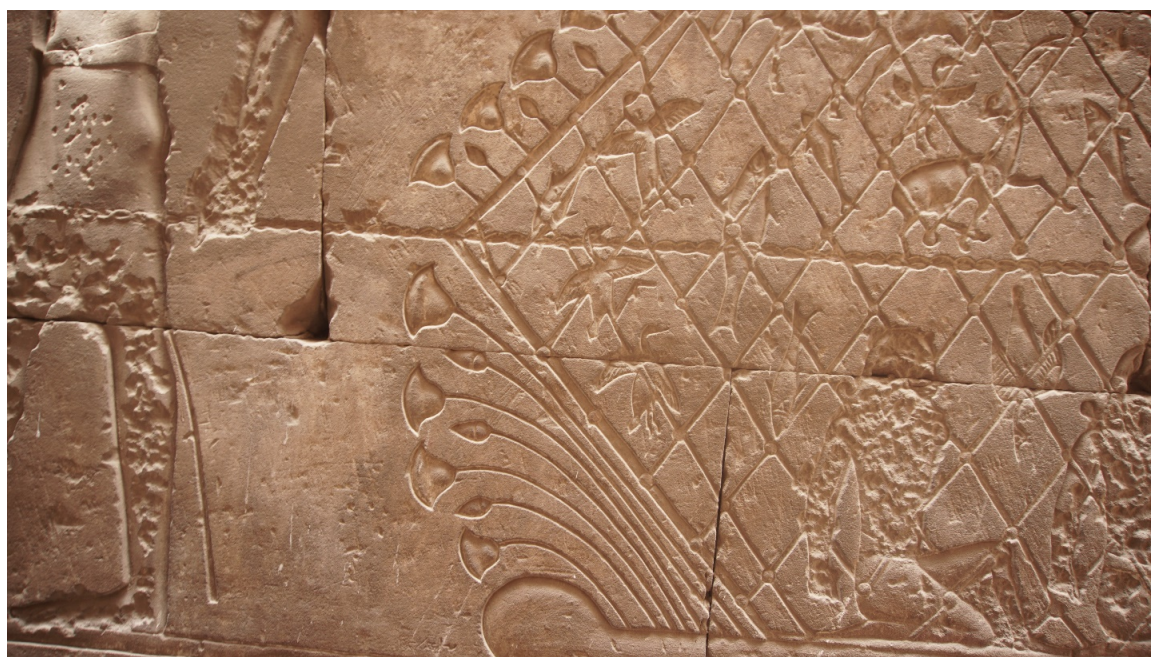

Figure 24. Part of a large relief depicting a net made from papyrus entrapping birds, animals, and captive humans. From the narrow alley at the east wall of the Edfu Temple. Photo by M.S., May 2019.

leopard-skin donning sm priest, entitled $\underline{t} t$ in front of Horus Narmer on the Narmer Palette, was to catch the shadow of a deceased as part of the statuette-making ritual recruiting the help of invocated animal spirits (Helck, 1987: pp. 21-30). This sm-shaman ritual, and the Mouth-Opening Ceremony which evolved from it, may have had their beginnings in the dwarf tamers and handlers of captured animals in predynastic Egypt. As tamers of wild animals, they were likely held in high regard explaining their possible role as later handlers of the shadowy netherworld spirits of both animals and humans, i.e. as the shamanesque $s m$ priests.

When viewed within this prehistoric context of over-powering and taming wild animals, the concept of writing from its earliest known beginnings to its full expression on the walls of Ptolemaic era temples three thousand years later appears to have been conceptualized by Egyptian scribes as an act of hunting and catching something alive, deeply rooted in now archetypal hunting rituals of an already sedentary people reaffirming their power over nature and, at once, seemingly imitating primordial creation. By analogy to the building of monuments on the ground below to recreate the sky above, writing in ancient Egypt can be similarly understood as a captive act of creation on Earth recreating the natural creative powers of the sky and the regenerative power of the $d w 3 t /$ the netherworld. This evidence suggests that the idea to use symbols to write in ancient Egypt was born from within the culture and mind-set of hunter-gathers, not sedentary agriculturalists and animal herders. We see evidence of the same phenomenon at Göbekli Tepe (Seyfzadeh \& Schoch, 2019).

With this context in mind, the association between the lioness Mehit and writing becomes more apparent: Witnesses who came to prehistoric Giza, the gate to the northern Delta territory of Egypt, viewing a lioness monument, split-in-two (which at times distant may have been partially flooded at its base), 
imagined the ultimate huntress of the animal world at the original place of creation, where the first words of creation had been spoken, thus arising from the flood waters and assuming megalithic material existence as living symbols of this creative act, where islands of reeds had initially grown on the shallower water of the receding flood (Figure 25) and birds like falcons had begun to settle, where animals congregated on the banks of the new river shore to drink, creating a hunter's paradise. The carved, chiseled, and inked outlines of written symbols in ivory, wood, stone, and woven papyrus sheets thus became the living shadows of the animals symbolically captured exactly like the divine words of creation were imagined as having manifested as monumental images in stone. The front and back of the lioness along with the shadowy crack in-between became the symbols of precious goods for the afterlife, the first words of creation of a newborn civilization, and the still visible, but immaterial shadow representing the invisible air $(\dot{S} w)$ of a new world created after the destruction of the old one by $R e$ and Mehit-wrt. Thus mythologically, Mehit is equivalent to or another form of the entity otherwise known as Tefnut, the Earthly moisture and watery counterpart to $\dot{S}_{W}$ (Mohamed Ibrahim, personal communication) ${ }^{13}$.

In fact, the very name Mehit is synonymous with "north" (Lower Egypt) and "papyrus" (Figure 26), and related to the word for cubit $m h$, used to measure the height of the yearly inundation, and also the word for flood in the personified name of Mehit-wrt, the Great Flood from which the d3jsw emerge in the story of creation as told in the Edfu Texts. The symbol of the papyrus bunch, Gardiner M16, on First Dynasty inscriptions denoted the concept of planning, conceiving, and creating (Helck, 1987: p.155-156; see also left pane of Figure 2, second symbol below the hole in the right upper corner). Therefore, the linguistic root of $h 3 t . t$, the frontal lion symbol representing the concept of front and first, is $h 3$, the primordial concept of creative conception as in first thought or idea. We conclude that prehistoric Egyptians not only intimately associated the lioness with the concept of writing, she personified the creative aspect of writing (catching ideas with a net of papyrus) $)^{14}$ immanently as the creative power of nature (ntr $r$ Allen, 2014: p. 54; Mohamed Ibrahim, personal communication) later also expressed in $h k 3$ (magical power; using Gardiner F22 on a standard; see e.g. the hk3 Mehit title of Wepemnefret atop his stele), and thus also became the icon of original creation timed to the First Time $z p t p$, when Mehit on Earth at Giza faced due eastward looking at both the Sun and her male counterpart $\mathrm{Ho}$ rakhty in the sky at dawn (Schoch \& Bauval, 2017: p. 210). This primordial, ancestral aura of Giza at the gate to the Nile Delta as the spiritual origin and place of creation is subtly captured in the royal throne (prenomen) title nswt

\footnotetext{
${ }^{13}$ Mohamed Ibrahim has suggested that Mehit might have been pronounced "Mouhet" to indicate the connection with moisture and water $(\mathrm{mw})$.

${ }^{14}$ Perhaps in contrast to Seshat (stht $3 b$ wj/The Seven-Horned) who personified the reed and ink used to "affix" the shadowy symbols onto palm leaves and papyrus. In fact, the name Seshat has Sumerian roots, i.e. $\dot{S} e \dot{S}^{\prime} W$ (hunt/net) indicating that her origins may locate to the prehistoric $B u$ to-Maadi Culture of Egypt's Delta, whose pictographic bi-syllabic script is now lost (Helck, 1987, ch. 11).
} 


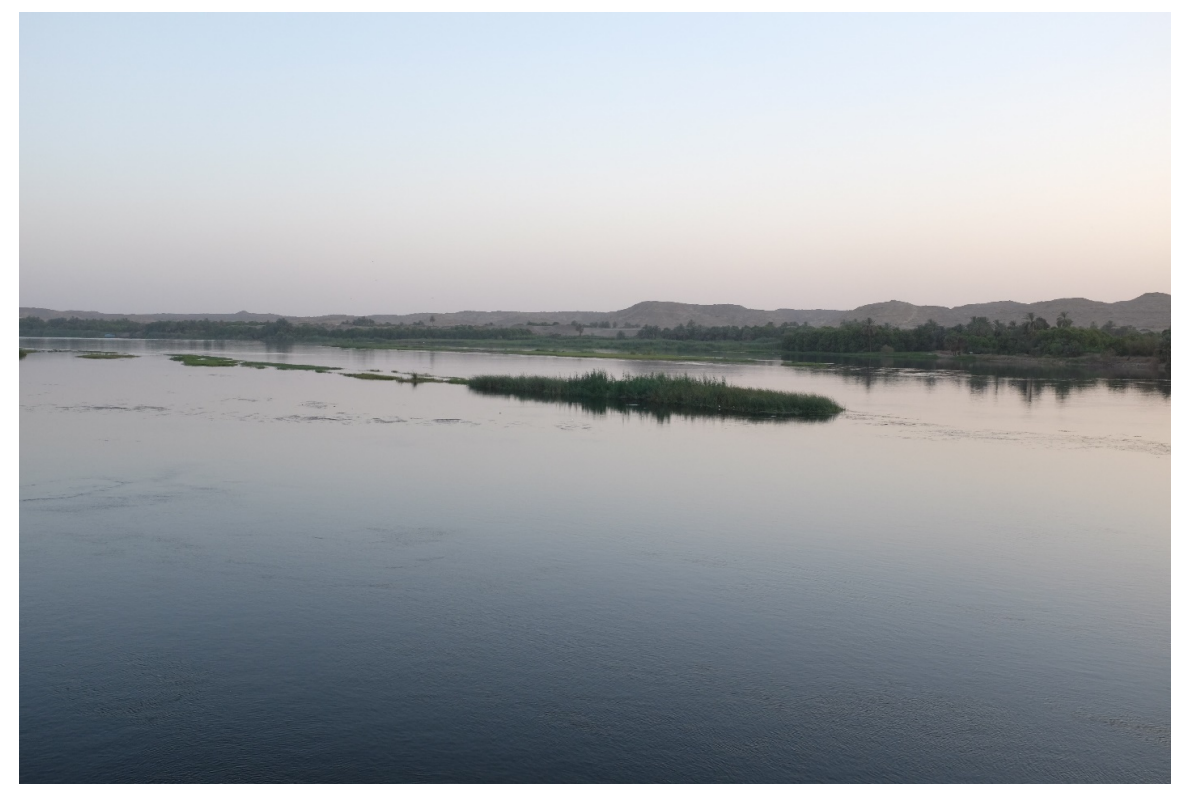

Figure 25. An island of reeds on the Nile in southern Egypt. Photo by R.M.S., June 2019.

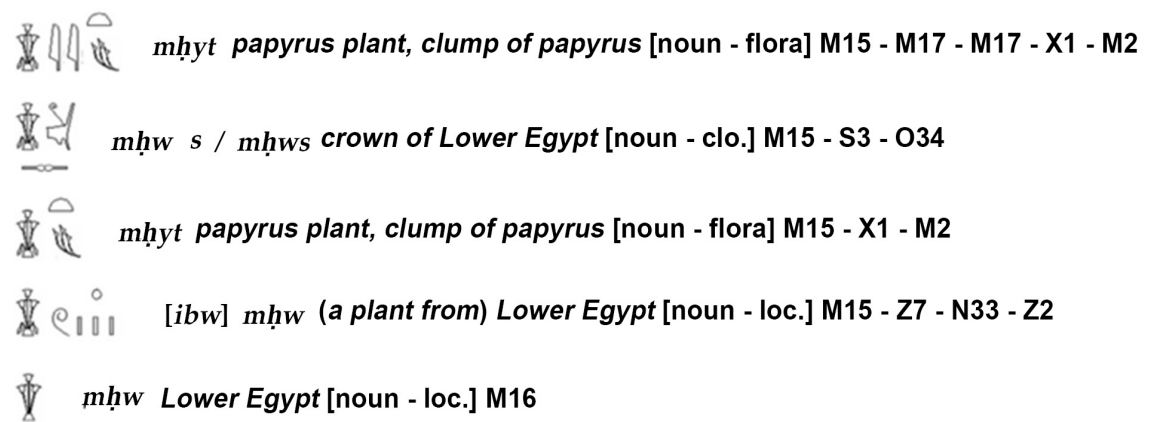

Figure 26. The name of the lioness Mehit is synonymous with the Egyptian words for north (Lower Egypt) and papyrus. From Vygus, 2015: p. 1005.

bjtj/Sedge and Bee of Egypt's king: The sedge, while typifying the south also represents the word king in general while the bee, symbolic of the north, also represents the legacy of the royal lineage (Allen, 2014: p. 83). Referring to the Shabaka Stone, Allen explains the relationship between creation and symbolic writing in the Memphite Theology as follows (Allen, 2014: p. 206):

It is significant that the text equates the creation of "everything" with the creation of "every divine speech". "Divine speech" $-m d w$-nt $r$, literally, "god's speech"-is the same term used to describe hieroglyphic writing (S 1.4). As we have learned, hieroglyphs have a dual nature: they are images of things in the real world, but they are also representations of ideas. By using the term "divine speech" to describe the created world, the author of the Memphite Theology implies that everything in creation is itself a kind of hieroglyph of the creator's original concept. In the same way, the beginning of the text refers to "evolution into the image of Atum" The word "image" - tj-is also used of hieroglyphic signs (the determinative is an adze, with which such signs could be carved). The 
physical world is thus an "image" of the original raw material of Atum in the same way that a hieroglyph is an "image" of a physical thing.

Therefore, we conclude that the original lion (or lioness) monument surviving the aftermath of the end of the Younger Dryas (circa 9700 B.C.E.) was possibly again witnessed, at the earliest, by prehistoric pastoralists and nomads seasonally venturing to the still flooded Nile Valley and Delta region from the western desert after the mid- $9^{\text {th }}$ Millennium B.C.E. (Hendrickx et al., 2010: p.18) or from the Levant. Possibly, however, the monument was still largely or completely submerged $^{15}$ and not witnessed until after the Nile's east-west expanse began to narrow when North Africa's climate began to dry during the Nile Delta's early Neolithic period ${ }^{16}$ (circa 5000 B.C.E.) permanently driving western desert pastoralists, perhaps such as the ancestors of the Tasians and the Merimde, to the Nile Valley and Delta (Hendrickx et al., 2010: pp. 15-35; Tristant \& Midant-Reynes, 2011: p. 46). Such early settlers might have witnessed the megalithic lion emerging from the Nile and seen it as the living manifestation, shaped from rock, of the original idea of creation, a gigantic set of three symbols ${ }^{17}$, Front, Fissure, and End, ascending from the waters of the receding waters of the epic flood which had been caused by a cosmic (solar) strike and Earthly upheaval.

This model predicts, or rather arguably generates the expectation, that the iconography of a split lion might have been depicted on later decorated-ceramic wares, votive items, and related objects from the Delta's mid-Neolithic material culture, after the Western Desert became uninhabitable (circa 4900-4400 B.C.E.; Hendrickx et al., 2010: p. 18). The extant material cultural remains of the Neolithic Nile cultural record discovered to date are still sparse, especially in the north of Egypt, possibly obliterated due to centuries of heavy intermittent Nile flooding explaining why no such evidence has surfaced to date, for example in Merimde layers I-V (circa 5000-3800 B.C.E.), in remains of the contemporary Fayum $A$ and Badarian cultures, and the later (after circa 3500 B.C.E.) Buto-Maadi culture from the western Delta, nor on ceramic ware from other sites in the middle Nile Valley like the earliest known Neolithic culture, the Tasians (Hendrickx et al., 2010: pp. 15-35). ${ }^{18}$

Other circumstances explaining the absence of the lion iconography in the extant Neolithic, prehistoric record of the Nile Valley and Delta is that neither the Tasians nor the Maadi decorated their black-topped, red-, and black-polished pots and only used geometric patterns on their "Tulip Cups" (Czerny et al., 2006: pp. 46-52; Caneva et al., 1987: pp. 108-109) while the Merimde people rarely included grave goods with their burials (Hendrickx et al., 2010, table p. 17). In ${ }^{15}$ The top of the head of the Great Sphinx is circa 100 feet above sea-level.

${ }^{16}$ The Neolithic period began at different times in different parts of the world. Egyptologists would refer to this period of human presence by the Nile as the early Neolithic (Tristant \& Midant-Reynes, 2011: p. 46).

${ }^{17}$ Selim Hassan analogously interpreted the Great Sphinx and pyramids as a monumentalized composite hieroglyph representing the setting Sun over the horizon between the mountains (Hassan, 1953: p. 243).

${ }^{18}$ Earlier Neolithic cultures in Egypt's western desert existed at Bir Kiseiba and Nabta Playa. 
common with the Great Sphinx monument's orientation towards the equinoctial sunrise however, predynastic Lower Egyptian burials positioned the deceased with the head south facing east (Stevenson, 2009: p. 6) in contrast to Naqadan burials in Upper Egypt which tended to place the head south facing west (Stevenson, 2009: pp. 3-4).

Regardless, we acknowledge an ostensible gap in the plausibly expected archeological record from the middle Nile Valley and Delta of circa 1600 years from 4900 to 3300 B.C.E., only at the end of which exists the so far earliest-documented evidence of the lion iconography in the Naqada culture of Upper Egypt's Abydos from tomb U-j (Dreyer, 1998, Tafel/Plate 30, \#69).

In late $4^{\text {th }}$ Millennium proto-dynastic Egypt, as in the Early Neolithic pre-pottery phase Anatolia of the $10^{\text {th }}$ Millennium B.C.E. (and earlier), we thus find evidence of the cultural imprint left by the power of such symbols when carved into megalithic stone structures. In our model, the awe-inspiring appearance of megalithic symbols became the true seed of civilization, not the method of food production. Symbols, then as now, inspired people to congregate, collaborate, invent, and implement new methods to produce food. The surpluses of such production enabled people to settle instead of wander and reduced the plight of making a living on-the-go. A sedentary lifestyle thus allowed mankind to shift its focus from making a living to observing the world, search for its meaning, and imitate it creatively in art and architecture, but it only became possible after, not before, hunter-gatherers built symbolic monuments and congregated (Seyfzadeh \& Schoch, 2019). This sequence may also explain the sparse cultural footprint surrounding some megalithic sites used for pilgrimage but not as a dwelling zone.

At Giza, another explanation may explain why no prehistoric remnants of hypothetical Sphinx builders have been found: Removal and appropriation. In his preliminary report, Kromer concluded that the footprint of a pre- ${ }^{19}$ and early dynastic culture was apparently razed from its original location somewhere within the pyramid district and on the plateau and the destroyed remnants and rubble were deposited outside of the district to the south of the Great Sphinx, the central field, and the causeway of Menkaure's pyramid (Kromer, 1972: pp. 34-35). The early dynastic style niched walls on the rock-cut mastabas of Kai (Figure 27; Hassan, 1941: pp. 29-40) and Khentkawes in the central field also suggest the presence of an older culture long before Khufu began to build at Giza (for a summary of the evidence see Reader, 2005: p. 54) ${ }^{20}$. We speculate, that the unique, rock-cut niching seen on the walls of these two mastabas, if they date to prehistoric times, may have even inspired this architectural style seen in the niched and paneled mudbrick structures used as tombs for the elite during the ${ }^{19}$ The evidence for a pre-dynastic presence comes from the way some of the pottery was painted which Kromer dated to Naqada II (circa 3500-3200 B.C.E.; Kromer, 1972, p. 32).

${ }^{20}$ Early dynastic Egyptian mastabas with niched exterior walls were made with mudbricks, for example at Giza (Mastaba V), Saqqara and Tarkhan. Niched mastabas conventionally dated to the Old Kingdom's Fourth Dynasty exist at Meydum. 

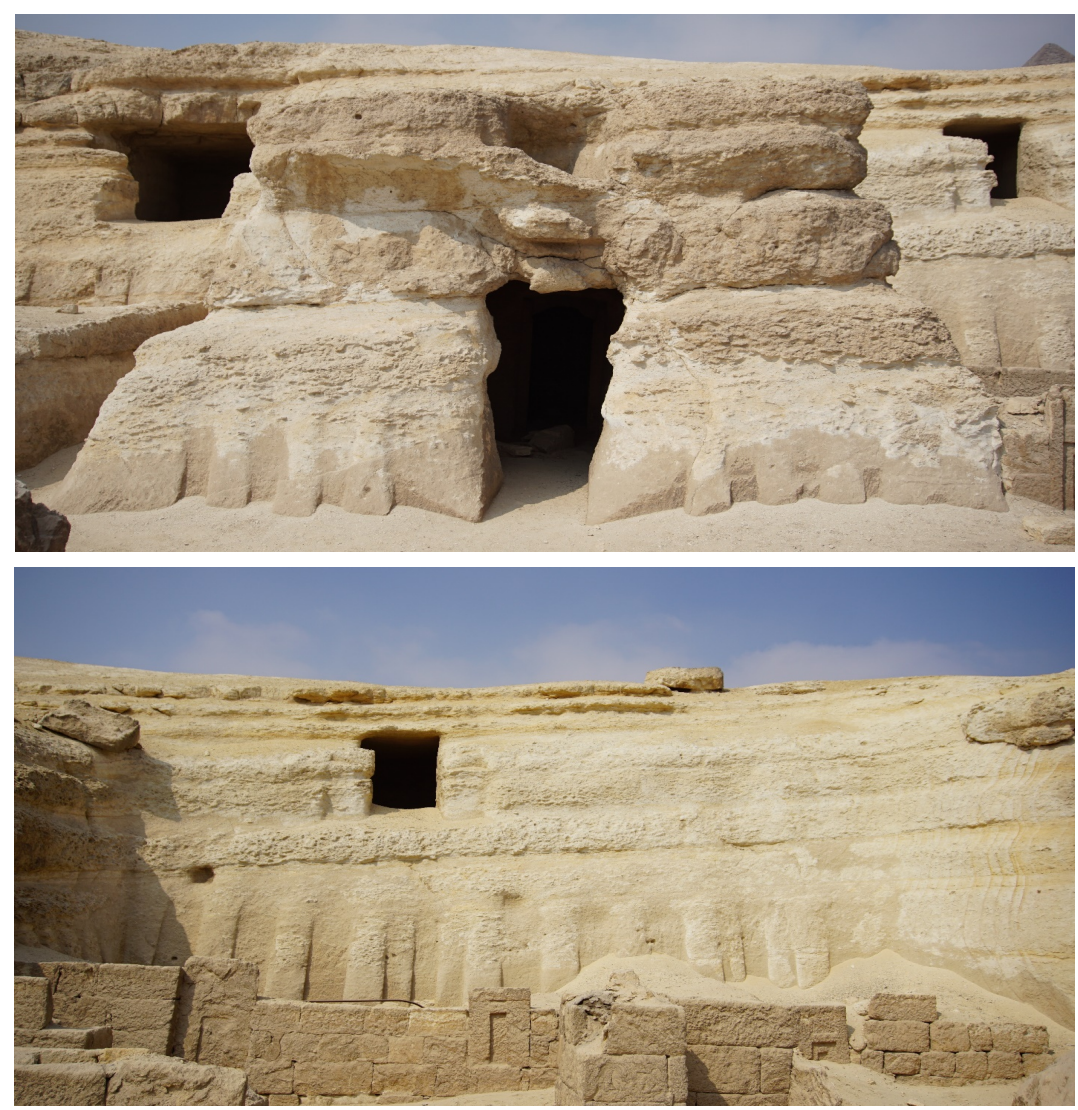

Figure 27. G8720, the lion face-like, rock-cut mastaba attributed to Prince Kai (late Fourth or early Fifth Dynasty) in the Central Field south of the causeway of Khafre's pyramid (top pane; Hassan, 1941: pp. 29-40). The niched and recessed exterior walls are more typical of early (First and Second) dynastic architecture and this façade style is depicted on a sealing found nearby (Kromer, 1972: p. 27) suggesting that Kai used a prexisting structure as his tomb (see also Reader, 2005: p. 54). The horizontal wind-and-sand erosion pattern of the limestone rock layers appears somewhat similar, but not identical, to that on the Great Sphinx and its enclosure walls, but the vertical and oblique erosion pattern observable there is not seen here (compare the bottom pane view of the mastaba attributed to Prince Kai to the views of the Great Sphinx enclosure walls seen in Figure 12 and Figure 14). A more typical, later added, Old Kingdon wall is seen in the foreground. Photos by M.S., September 2018.

early dynastic times of unified Egypt and the palace discovered at Hierakonpolis (Friedman \& Bussmann, 2017: p. 81).

The Idea of an Archive under the Monumental Lioness, "The Hall of Records". The foregoing discussion raises the question where megalithic building skills and symbolic writing originated, if not grown out of a sedentary lifestyle but a nomadic, hunter-gatherer lifestyle. Did these early pillars of civilization originate locally and independently at different prehistoric megalithic sites around the world, or did they originate in one place and diffuse to other areas, or should we consider a combination of these two modes? A related idea, the esoteric, alternative theory of the "Hall of Records" under the Sphinx, is based 
on the idea that a prior people (iconized by Plato's Atlantis Story), observed the Earth and the sky, formed advanced knowledge, developed sophisticated tools, built stone monuments, recorded and stored their heritage for posterity in an archive physically and symbolically protected under the Great Sphinx monument. From this archive, the stored knowledge and skill seeded civilizations around the world. In a related theory, the knowledge and skill were carried to these other places by mythical beings or sages, and this is where the number seven prominently features: The seven baboons $\underline{d} 3 j s w$, the seven fish and bird Apkallu/Abgallu of Sumer (Oppenheim, 2004: pp. 171-173), both water-born agents, and the seven-horned Seshat (stht $3 b w j)$, patron goddess of writers, archivists, surveyors, and astronomers, for example.

According to our model of megalithic symbols, the monuments themselves could have served as the archives which means the "hall" is symbolic and the "records" are monumental serving as the seeds of civilization. Another way to explain the idea of an archive of accumulated knowledge is a physical space under a monumental shrine serving as a depository and repository. This concept was documented by the ancient Egyptians themselves in the theological (e.g. Coffin Texts), literary (e.g. Papyrus Westcar), and medical (e.g. Papyrus Ebers) literature (Sherbiny, 2017: pp. 136-151). The term 'fdt variously referred to a chest, box, or even a space, cabin, chamber, or cave, under the feet of a statue or shrine of a deity in which written records (' $f t t$ ) were stored (Sherbiny, 2017: pp. 149-150). In Harris Magical Papyrus 501 ${ }^{21}$, for example, a document attributed to Thoth is said to have been kept under the feet of Re-Horakhty at Heliopolis ${ }^{22}$. Horakhty is a name associated with the Great Sphinx on the New Kingdom Dream Stele and several votive steles found in the vicinity (Hassan, 1953: pp. 234-268); Horakhty is synonymous with Re-Horakhty, the father of Horus Behedety from the Edfu Texts, and Robert Bauval has found textual evidence that this was the name of the celestial sphinx recognized in the constellation Leo in the Pyramid Texts of the Old Kingdom (Schoch \& Bauval, 2017: pp. 193, 205, 221-226). The Edfu Texts speak of "a book which fell from the sky north of Memphis" ( $m \underline{d} 3 t$ tn hl $3 j n$ pt mhtj jnbw hd $)$ ) in which instructions were written according to which Ptolemy X or XI was to build the girdle wall enclosing the temple (Kurth et al., 2014: p. 7/Émile Chassinat 6, 4).

Finally, the oldest evidence of a papyrus scroll hidden underground comes from the First Dynasty: This papyrus sheet was uninscribed and is the first known example to date of this material used in the history of Egypt. Here it was symbolically placed by itself in a finely made round wooden box and buried with Hemaka (circa 2900 B.C.E.) inside a magazine room in his tomb at Saqqara, ${ }^{21}$ New Kingdom, $20^{\text {th }}$ Dynasty. URL: https://www.britishmuseum.org/research/collection_online/collection_object_details.aspx?objectId $=114260 \&$ partId=1.

${ }^{22}$ See Budge, Sir E. A. W., 2018. URL: https://books.google.com/books?id=ONKSDwAAQBAJ\&lpg=PT236\&ots=vil0o3Ng1W\&dq=papyr us\%20harris\%20hymn\%20shu\&pg=PT236\#v=onepage\&q\&f=false. 
S3035 (Emery, 1938: p. 41; Plate 23a). The Pyramid Texts of Unas (circa 2350 B.C.E.) from the end of the Fifth Dynasty are of course an underground pyramid chamber-and-corridor system onto whose walls the accumulated records of Egyptian theology were carved.

The concept of written scrolls hidden underground as in a "Hall of Records", generically at least, is therefore much older than even the Egyptian Middle Kingdom (2040-1782 B.C.E.) and long predates the later lore generated during the Hellenic, Coptic, Arab, and Modern Western eras, which have popularized a cultic caricature of it across the world dismissed as a myth nowadays by scholars and sceptics. With respect to the Great Sphinx, nevertheless, a subterranean, ostensibly man-made void (estimated to be approximately 12 meters $\times 9$ meters at an approximate depth of 5 meters) has been seismically located (Low Velocity Anomaly A; Dobecki \& Schoch, 1992; Schoch in Schoch \& Bauval, 2017: pp. 81-82; Figure 28). Several drillings around the Great Sphinx have been conducted since 1978 (Lehner, 1991: pp. 88-89), but none where this seismic signal appears (Figure 29). The possibility of another man-made chamber under the Great Sphinx is further supported by what Auguste Mariette observed at the bottom of the major fissure when he first cleared it (Mariette, 1857: p. 95; bold emphasis ours):

Un autre trou existe dans le dos et vers la naissance des cuisses. Le P.Vansleb en parle ainsi: “...elle a par derrière une cave sous terre, d'une largeur propor-tionnée à la hauteur de la teste, dans laquelle j’ay regardé par une ouverture qui y est, et qui n’a pu servir à autre chose, qu'à y mettre le corps de quelque mort". J'ai fait nettoyer le trou jusqu'au fond, et, en effet, quand on y regarde d'en haut, il semble qu'il se termine par une chambre. Mais, malgré son apparence de puits funéraire, ce n'est qu'une fissure agrandie qui va en s'élargissant, et qui se termine par un vide assez spacieux ménagé précisément dans le plein des cuisses.

This chamber, if it exists, may correspond to Low Velocity Anomaly B (Figure 28) also identified utilizing seismic refraction (Dobecki \& Schoch, 1992; Schoch in Schoch \& Bauval, 2017: pp. 81-82).

Previously, we have interpreted the bent rod symbol (which we named the "JAW Sign", commemorating the work and legacy John Anthony West) to be a key to a lock, or perhaps a bolt, securing a door and thus identifying Mehit as a monumental, locked facility such as an archive or library (Seyfzadeh et al., 2017). The object depicted by the JAW Sign is ostensibly inserted with one, two, or three (sometimes linked) prongs into the back of the image of Mehit depicted on First Dynasty sealings dated to a period between Horus Narmer and Horus Den and on Old Kingdom tomb reliefs from the mastabas of Hesy-Re, Wepemnefret, and Hemiunu. If Anomaly A is indeed human-made, it could be the elusive archive under the Great Sphinx, the real "Hall of Records", but without a direct probe definitive proof of it will likely never be obtained and whatever records stored therein, be they written symbols, relics, or some other form of stored communication, could have already been lost to time and decay, especially since 


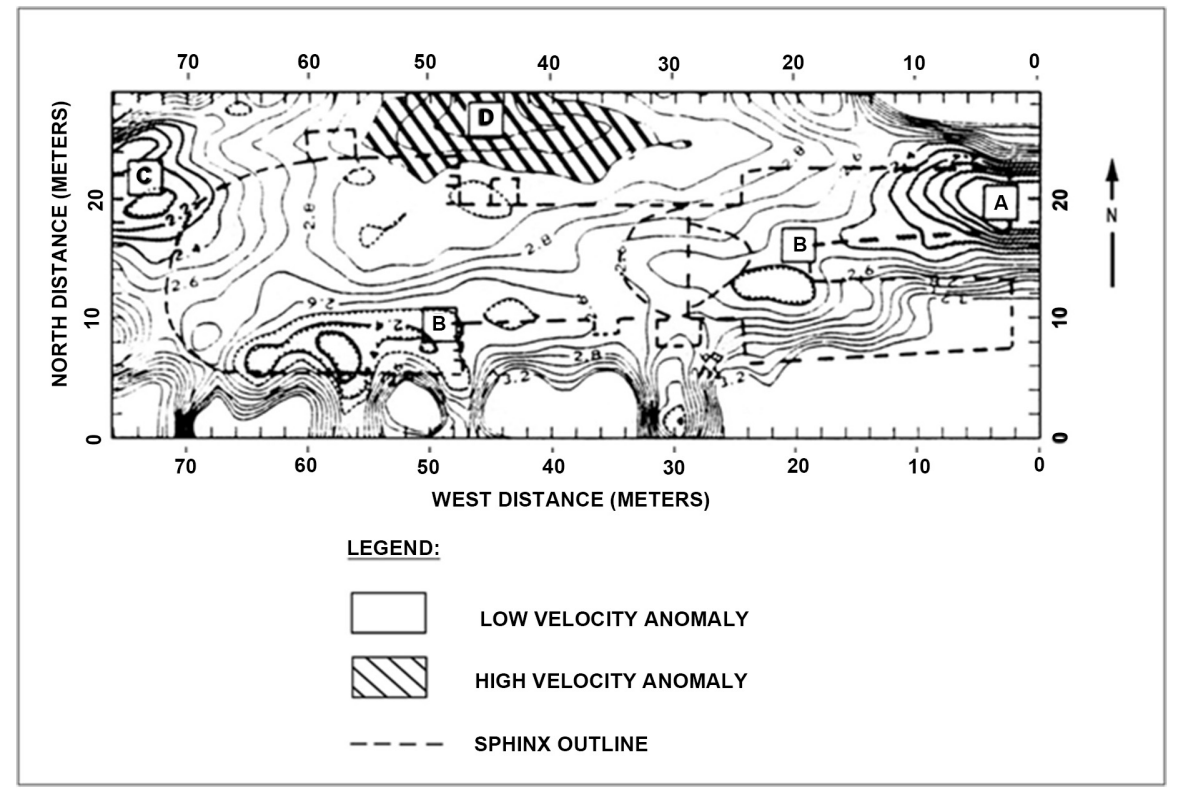

Figure 28. Seismic velocity map beneath the Great Sphinx as determined by refraction tomography (see Dobecki \& Schoch, 1992). The outline of the Great Sphinx is shown as a dashed line. Illustration courtesy of Robert Schoch and Catherine Ulissey.

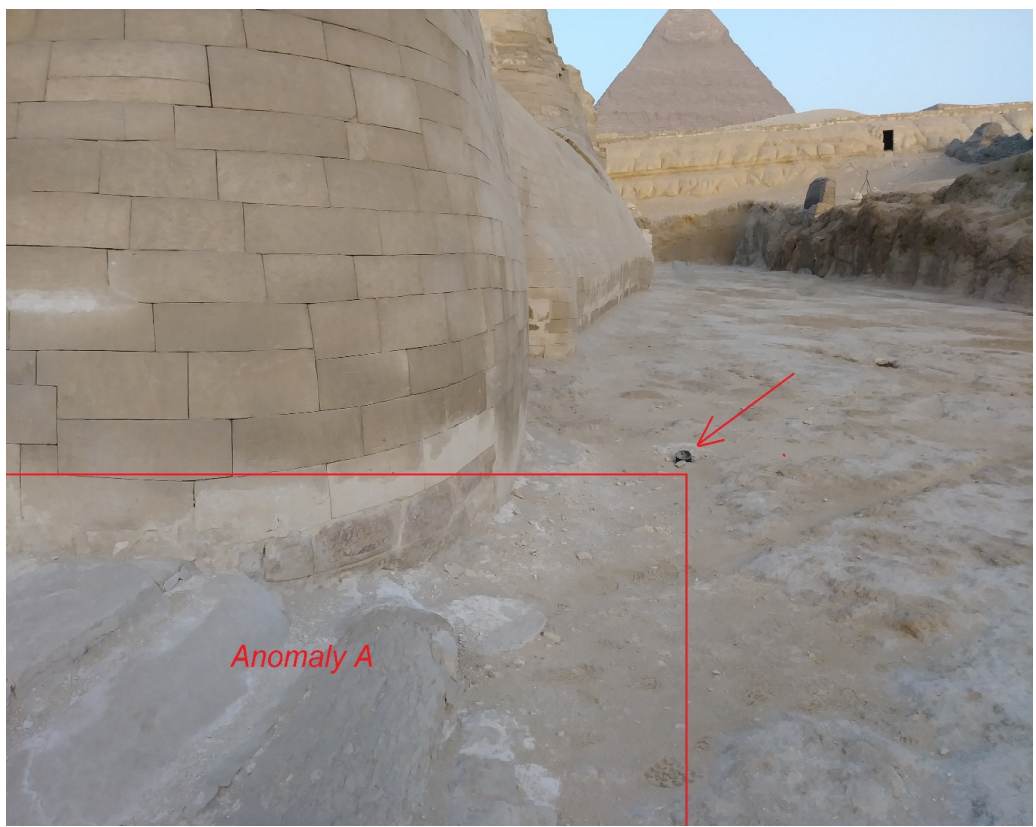

Figure 29. View inside the Sphinx enclosure looking west towards the pyramid of Khafre from the east. The northern, left forepaw is visible. The red arrow shows a capped drilling head left by a 2009 probe conducted by Cairo University, Zahi Hawass, and Mark Lehner for the then Supreme Council of Antiquities (now the Ministry of State for Antiquities). This drill went circa 10 meters into the lower member bedrock of the Sphinx ditch at an approximate impact angle of $45^{\circ}$ (Video URL: https://youtu.be/3qGzfZHWbZE). The approximate northwest corner of Anomaly $A$ is shown in red. It extends east and south of the position of this probe and only barely, if at all, overlaps with it. Photo by M.S., June 2019. 
the water table under the Sphinx enclosure has probably reached a level of at least 5 meters below the surface.

Here, however, we would like to report new evidence to support the idea that the bent $\operatorname{rod}(\mathrm{s})$ over Mehit may have been a key as we have proposed. We previously predicted that there is likely not a single word in the ancient Egyptian language which utilizes the JAW Sign by itself (Seyfzadeh et al., 2017: p. 172). Here, we maintain that this statement is correct, but wish to qualify it. Likely, the northern territory of prehistoric Egypt's Delta before unification spoke and wrote in a pictographic language different from the phonetic script (the earliest written symbols of which are found in Tomb U-j) of the Nile Valley and southern Egypt, the homeland of the Thinite kings beginning with Horus Narmer (Helck, 1987, chapter 11). This Buto-Maadi-native tongue is now a ghost language, since no inscriptions in it have been found to date with the sole possible exception of an early dynastic mud seal imprint (i.e. a sealing) with apparently non-Egyptian symbols discovered south of the Great Sphinx at Giza (Kromer 1972: pp. 27, 33-34). Some of these lost foreign symbols, however, survived in what became the early Egyptian language after unification circa 3000 B.C.E. One such symbol is the bent rod which we previously coined as the JAW Sign.

This sign can be seen painted onto jars from royal tombs in Abydos next to a sign resembling Gardiner W8 (Figure 30). W8 is likely also a symbol which was used in the Buto-Maadi language zone, where it had the phonetic value of $g 3$ and was later absorbed into the dynastic state language of hieroglyphic Egyptian where it later assumed a completely different sound value, skty. The original meaning of the word $g 3$ in native-Buto is unknown, but the sound of this word resembles g3 / $g 3 w t$. In Egyptian, g3 / $g 3 w t$ possibly meant tribute(s)/tax(es) (Vygus, 2015: p. 2339) or oil (Figure 30), which in the language of predynastic and early dynastic Egyptian from the south were $j p w$ and h3t.t, respectively (Helck, 1987: pp. 186, 171). Therefore, tributes from the Delta might have been labelled with the native-Buto symbol W8, because the Upper Egyptian royal scribes would have read this as tributes, for example in the form of oil shipments, from the conquered zone.

The JAW Sign, written together with W8, probably denoted the origin of the tribute in the Delta as was common practice on oil tags. Oil from the Delta was famously made in B3st / Bubastis. We therefore suspect that the JAW Sign had a phonetic value of either $B u-B a$ or $B a-B u$, which in Egyptian meant "Seat of the Soul" or "Soul Seat", the same meaning as is given by the commonly known word for the city, Ba-Set (Figure 31). Since there are some reasons to suspect that traders who had settled in the Delta had cultural contact with contemporary Sumerians of the Uruk Period in Mesopotamia (4000-3100 B.C.E. $)^{23}$ and since the native-Buto ghost language was evidently distinct from Upper Egyptian, we asked, (contra Ward, 1964: pp. 35-39), if there might indeed be a linguistic link between the former two people.

${ }^{23}$ This is based on the Sumerian cultural footprint evident is some Egyptian art and architecture (for a review see for example the discussion by Helck, 1987, ch. 10). 


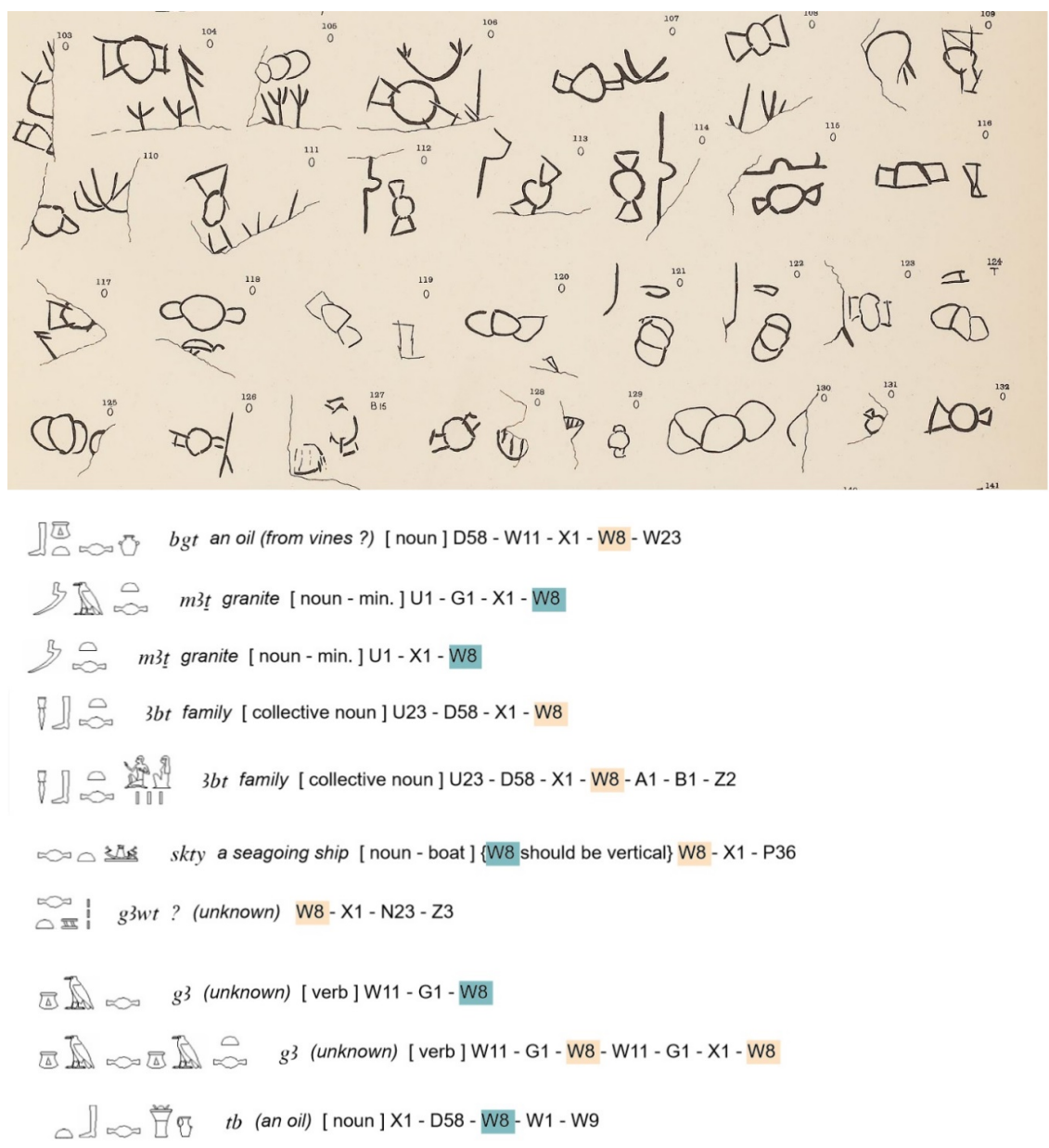

Figure 30. The upper pane shows pottery markings found on jars in the royal tombs of Abydos by Petrie (Petrie, 1901, Plate LVa). The bent-rod JAW Sign which Petrie called a "yoke" sign, is associated with a "winged ring" sign (second row) possibly identical with Gardiner W8 (see bottom pane). Used as a determinate, it appears in three contexts: Granite, family, and oil. Used phonetically, it appears to have two different values, skty and g3.

The Akkadian/Sumerian dictionary assigns the meaning of opening, doorway, door, or gate (keeper) to the word "babu", and the meaning of bend to "ga-babu" (Figure 31). We therefore reconstruct the meaning of the JAW Sign in the following way: The object in symbol-form meant "open/doorkeeper" in native-Buto (e.g. we suggest Oppenheim, 1998: pp. 14-27; esp. pp. 26-27) and when combined with Gardiner W8 it meant "bend/encircle/curve". One can reasonably derive the meaning of "bent opener" (e.g. key) from this, if this language was based on a bi-syllabic word design as Helck also suspects (Helck, 1987, chapter 11); however, no sense at all may have been made in the language of native-Buto by combining W8 and the JAW Sign. In the language of Upper Egypt, however, the combination of these two symbols sounded like the words $g 3 w t b 3 b w$ "Oil-Babu", i.e. oil tribute from Baset / Bubastis, which is why they were painted on jars shipped to Abydos and marked as highly coveted grave goods for the afterlife. In principle, this phonetic use of words which meant one thing (or even 
kapāpu $(k a b a \bar{b} b u)$ v.; 1. to bend, to curve, to wrap around, 2. I/2 to bend, curve (in trans.), 3. kuppupu to bend, to curve, 4. sukpupu to cause to bend, 5. IV to become bent; from $\mathrm{OB}$ on; I ikpup - ikap pap - kapip, I/2, II, III, IV; wr. syll. and GILIM, GAM; cf. kippatu, kippu, kuppupu.

[x]-x BULÙ $=k a-p a^{b a}-p u$ A VI/1 $: 178$.

patālu kapālu [...] ka-pa(!)-pú (for contex see kapâlu lex. section) CT 3110 r.(!) iii 15 (ext. comm.); tu-kap-pap 5R $45 \mathrm{~K} .253$ viii 48 , but tu-gab-bab ibid. 34 (gramm.).

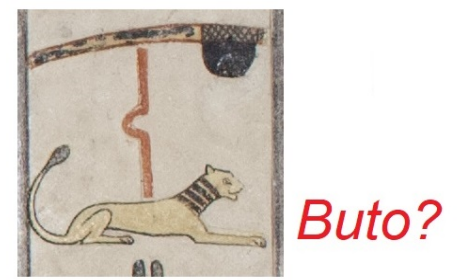

\title{
Akkadian/Sumerian
}

\author{
gabābu (to bend) see kapāpu. \\ ga|bābu (sling) see kabābu.
}

bābu A s.; 1. opening, doorway, door, gate, entrance (to a house, a building or a part thereof, to a palace, a temple or part thereof, to a city, to a cosmic locality), 2. city quarter, 3. opening of a canal, of an object, of a part of the body, 4. in $b \bar{a} b$ ekalli umbilical fissure of the liver, 5. opening, beginning (in transferred mngs.), 6. item, section; from OAkk. on; pl. bäa bu, bābānu (rare in SB), bābātu (passim from OB on); wr. syll. and KÁ (in mng. 4 ME.NI for $b \bar{a} b$ ekalli); cf. $b \bar{a} b \bar{a} n u$, $b \bar{a} b \bar{a} n \hat{u}, b \bar{a} b u \mathrm{~A}$ in $r a b b \bar{a} b i, b a \bar{b} u \mathrm{~A}$ in $\breve{s} a b \bar{a} b$ ekalli, $b \bar{a} b u \mathrm{~A}$ in $\check{s} a b \bar{a} b i, b \bar{a} b u \mathrm{~A}$ in $s a$ muhhi $b \bar{a} b i$, gagh in $\breve{s} a b \bar{a} b$ gagî.

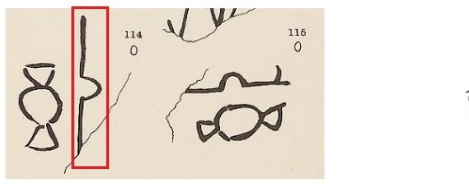

$$
\begin{aligned}
& \text { b3st Bubastis [ noun - loc. ] W1 - X1 - O49 } \\
& \text { st place [noun ] Q1 - X1 } \\
& \text { bst place, thing [noun ] D58 - G43 }
\end{aligned}
$$

$$
\begin{aligned}
& \text { (4) I. }
\end{aligned}
$$

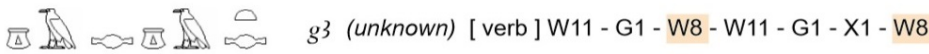

$$
\begin{aligned}
& \sqrt{\Delta} \infty \int_{0}^{\square} \quad \text { bgt an oil (from vines ?) [ noun ] D58 - W11 - X1 - W8 - W23 } \\
& \text {. } 1 \text { m } \# \text { r tb (an oil) [ noun ] X1 - D58 - W8 - W1 - W9 }
\end{aligned}
$$

Figure 31. The bent-rod symbol (JAW Sign) sounded like the word for Bubastis in the Upper Egyptian language, but phonetically resembles "babu" = open in Akkadian/Sumerian (Oppenheim, 1998: pp. 14-27), which may have shared a common linguistic root with the native-Buto ghost language. When combined with Gardiner W8 g3, the two symbols sounded like g3-babu Oil/Tribute from Bubastis in Upper Egyptian but would have possibly meant "ka-papu/ga-babu" = bend in Akkadian/Sumerian (Oppenheim, 1995: p. 1; Oppenheim, 2008: pp. 175-176) and thus possibly also in the lost language of native-Buto.

nothing) in one language to express something different and unrelated in another (or even the same) language became firmly embedded in the later Egyptian language in the form of Group-Writing (Allen, 2014: pp. 260-263) and hk3 Magic (Seyfzadeh \& Schoch, 2018: pp. 109-110).

We therefore observe that the JAW Sign was initially used in at least two foreign (from Buto) loaner words in the language of unified Egypt, "ga-babu" = Oil/Tribute from Baset and "babu-urmalw" (Akkadian/Sumerian "ur-mah-hu" "ur-ma-lw" = colossal lion; Oppenheim, 2010: p. 232) = Gatekeeper of The Great Lion, i.e. the monumental lioness Mehit at Giza in our reconstruction ${ }^{24}$. We would like to point to the intriguing similarity between Akkadian "ur-mah-hu" and Egyptian ${ }^{24}$ Of note, the same words in hieroglyphic Egyptian wr $m 3 j$ "Great Lion" were found painted on pottery shards at the Wadi al-Jarf, Khufu's Harbor (Tallet, 2012: p. 168, left piece). 
Mehit-wrt (two words transposed), the Great Flood. However, as far as we can tell the JAW Sign was never used in any native-Egyptian word. If our reconstruction of the native-Buto meaning (open/gatekeeper) and sound ("ba-bu") of the JAW Sign is correct, it further supports our theory that the JAW Sign-over-Mehit, an originally native-Buto construct (since Mehit was at Giza) was concretely meant to depict a key, literally an opener, inserted into a facility in the shape of a monumental lioness, located, as we have argued, at Giza long before Khafre. This is also the meaning of the bent-rod lioness dual symbol adopted by the later state language of dynastic Egypt, where it became part of an exclusive title carried by only the highest and most trusted officials at the royal court (Seyfzadeh et al., 2017). We suggest that this locked facility was the true "Hall of Records", an archive or repository of stored knowledge under the left forepaw of Mehit, where an actual man-made void evidently exists, so far seemingly unexplored. Whether this archive was made before or after the creation of Mehit is unknown and only its contents, if recoverable, may definitively date it and Mehit herself.

Given the above analysis of a Sumerian origin of the JAW Sign, another possibility arises: The northern and southern language zones of Egypt before unification incorporated the imagery of a monumental lioness at Giza split in half by the major fissure in two different, but related ways: Upper Egyptians in the language zone of Hierakonpolis and Abydos interpreted the major fissure through the lion(ess) monument as something between its front and back, i.e. "intermediate" or "medium" and Lower Egyptians in the language zone of Egypt's Delta centered on Buto interpreted this geological feature as an opening and hence used the JAW Sign to represent a gateway, for example, to the monument's interior.

\section{Conclusion}

In this paper, we have presented evidence that a prehistoric monumental lioness at the foot of the Giza Plateau inspired the creation of distinct symbols used in writing and the mythical story of creation based on distinct physical features of the statue, in this case damage possibly caused by a shifting Earth or by a solar strike from the sky. This evidence suggests that a megalithic lion or lioness existed at Giza at least as early as Egypt's proto-dynastic phase and thus contradicts the conventional Reisner/Hassan/Ricke/Lehner/Hawass model promoted over the last century which proposes that the Great Sphinx was originally carved in its entirety seven centuries later during the Fourth Dynasty. Our findings make two major, testable predictions: First, evidence of a prehistoric culture possibly involved in the creation of the original lion(ess) monument may still exist in the void beneath its left paw. This area has never been probed even though seismic refraction testing suggests one exists there and has correctly identified another void by the northern flank. Second, our reconstruction of the bent rod JAW Sign's meaning predicts that the language spoken and written by 
the Buto-Maadi, and possibly even older cultures in the Delta, is related to Sumerian supporting the idea of cultural contact and influence (e.g. Frankfort, 1924: p. 118). We propose that it may be possible to reconstruct this ghost language in a manner analogous to the method we demonstrate in this paper with the JAW Sign.

In ancient Anatolia, we have proposed that prehistoric bull-like (or Orion-like) pillars adorned with symbol-like carvings at Göbekli Tepe inspired the later Luwian hieroglyphic language. In both cases, the original meanings of the constructions may have been related to the images imagined in the night sky possibly invoking ideas of a higher power and creator. After a great world-wide catastrophe erasing the cultural footprint of these cultures, the only remnants were the megaliths (including the original Sphinx in the form of the lioness Mehit). In our model, these megaliths became the seeds of new civilizations, not the advent of surplus food production from domesticated plants and animals as has been the dominant archeological paradigm over the last century.

The civilization-organizing mechanism in our model is congregation and shared belief. People come together when they share a common goal, such as escaping hardship or aspiring to a common ideal, like the belief in a higher power and an afterlife where they hope to reunite with those they lost. Such beliefs also alleviate the fears of untimely death, for example the fear of an unnatural death due to environmental catastrophes, and the permanence of death. The unintended, but beneficial, consequence of prehistoric congregation was agglomeration, enhanced economic productivity due to more efficient communication, basically prehistoric networking. Ideas and implementations for a better life evolved faster from these prehistoric think tanks created when people congregated under the power of symbols.

Symbols, because they can inspire belief, power this people-organizing mechanism. Symbols can invoke fear and hope. Symbols can guide the lost, unite smaller bands of people, and bring together people who would otherwise compete. And so, it is the symbolic power of megaliths left by prior civilizations doomed to obscurity in the annals of history in the aftermath of catastrophe, their awe-inspiring symbolic appearance that is, which ultimately seeded and inspired new civilizations, which themselves arose and fell, nevertheless continuously preserving the central, immortal thread of the divine culture of humanity and our ancestors.

\section{Acknowledgements}

We thank the Organization for the Research of Ancient Cultures (ORACUL) for logistical research support while in Egypt. We thank the Egyptian Ministry of Antiquities for allowing access to the Sphinx Enclosure, the Osireion, and various areas at Edfu Temple. We thank Mr. Mohamed Ibrahim for various fruitful discussions and logistic help while in Egypt. The following people have helped with reviewing and commenting on the manuscript: Messrs. Jean-Paul Bauval and James Fields. 


\section{Conflicts of Interest}

The authors declare no conflicts of interest regarding the publication of this paper.

\section{References}

Allen, J. P. (2014). Middle Egyptian. An Introduction to the Language and Culture of Hieroglyphs (3rd ed.). Cambridge: Cambridge University Press. https://archive.org/details/ALLEN2014MiddleEgyptianAnIntroductionToTheLanguage AndCultureOfHieroglyphs

Bestock, L. (2009). The Development of Royal Funerary Cult at Abydos: Two Funerary Enclosures from the Reign of Aha. Wiesbaden: Otto Harrassowitz Verlag.

Budge, Sir E. A. W. (1978). An Egyptian Hieroglyphic Dictionary (Vol. II). New York: Dover Publications, Inc.

Budge, Sir E. A. W. (2018). The Literature of Ancient Egypt: Including Original Sources: The Book of the Dead, Papyrus of Ani, Hymn to the Nile, Great Hymn to Aten and Hymn to Osiris-Sokar. Prague: E-artnow.

Caneva, I., Frangipane, M., \& Palmieri, A. (1987). Predynastic Egypt: New Data from Maadi. The African Archaeological Review, 5, 105-114. https://doi.org/10.1007/BF01117086

Chassinat, É. (2014). The Cross-References to the Early Work of Émile Chassinat (1868-1948) on Edfu are from Kurth et al.

Czerny, E., Hein, I., Hunger, H., Melman, D., \& Schwab, A. (2006). Die Tulpenbecher und ihre Verwandten. In Timelines-Studies in Honour of Manfred Bietak (Vol. 2, pp. 45-54). Leuven: Leuven University Press.

Dobecki, T. L., \& Schoch, R. M. (1992). Seismic Investigations in the Vicinity of the Great Sphinx of Giza, Egypt. Geoarchaeology: An International Journal, 7, 527-544. https://doi.org/10.1002/gea.3340070603

Dobrev, V. (2004). Secrets of the Sphinx Revealed. https://youtu.be/Dgf-0IT3aQI

Dreyer, G. (1998). Umm el-Qaab I: Das prädynastische Königs-grab U-j und seine frühen Schriftzeugnisse. Deutsches Archäologisches Institut, Abteilung Kairo, Archäologische Veröffentlichungen 86. Mainz: Verlag Philipp von Zabern.

Droux, X., \& Friedman, R. F. (2007). The Columned Hall at HK6 and Other Wonders. Nekhen News, 19, 7-9.

Emery, W. B. (1938). The Tomb of Hemaka. Cairo: Government Press, Bulaq.

Emery, W. B. (1954). Great Tombs of the First Dynasty. Vol. II. Egypt Exploration Society. London: Oxford University Press.

Fairman, H. W. (1935). The Myth of Horus at Edfu: I. The Journal of Egyptian Archaeology, 21, 26-36. https://doi.org/10.1177/030751333502100103

Fischer, J., Hammerschmidt, K., Cheney, D. L., \& Seyfarth, R. M. (2002). Acoustic Features of Male Baboon Loud Calls: Influences of Context, Age, and Individuality. Journal of the Acoustical Society of America, 111, 1465-1474.

https://doi.org/10.1121/1.1433807

Frankfort, H. (1924). Studies in Early Pottery of the Near East. Volume I: Mesopotamia, Syria and Egypt and their Earliest Interrelations. London: Royal Anthropological Institute of Great Britain and Ireland.

Friedman, R. (1996). The Ceremonial Centre at Hierakonpolis Locality HK 29A. In J. 
Spencer (Ed.), Aspects of Early Egypt (pp. 16-35). London: British Museum Press.

Friedman, R., \& Bussmann, R. (2017). The Early Dynastic Palace at Hierakonpolis. In M. Bietak, \& S. Prell (Eds.), Palaces in Ancient Egypt and the Ancient near East Vol. I: Egypt, Contributions to the Archaeology of Egypt, Nubia and the Levant V(pp. 79-99). Vienna: Austrian Academy of Sciences Press.

Guilhou, N. (2010). Myth of the Heavenly Cow. In J. Dieleman, \& W. Wendrich (Eds.), UCLA Encyclopedia of Egyptology. Los Angeles, CA. http://digital2.library.ucla.edu/viewItem.do?ark=21198/zz002311pm

Hamilton, K. (2018). The Osireion. A Layman's Guide. https://www.academia.edu/37568156/The_Osireion_A_Laymans_Guide

Hassan, S. (1941). Excavations at Giza (Vol. 3). Cairo: Government Press.

Hassan, S. (1949). The Sphinx. Its History in the Light of Recent Excavations. Cairo: Government Press.

Hassan, S. (1953). The Great Sphinx and Its Secrets. Historical Studies in the Light of Recent Excavations. Cairo: Government Press.

Hawass, Z. (1993). The Great Sphinx at Giza: Date and Function. In Sesto Congresso Internazionale di Egittologia (Vol. 2, pp. 177-195). Turin: International Association of Egyptologists.

Helck, W. (1987). Untersuchungen zur Thinitenzeit. Wiesbaden: Otto Harrassowitz Verlag.

Hendrickx, S., Huyge, D., \& Wendrich, W. (2010). Worship without Writing. In W. Wendrich (Ed.), Egyptian Archaeology. Blackwell Studies in Global Archaeology (pp. 15-35). Chichester: Wiley-Blackwell.

Hölscher, U., Borchardt, L., \& Steindorff, G. (1912). Das Grabdenkmal des Königs Chephren. Leipzig: J. C. Hinrichs'sche Buchhandlung.

Kahl, J. (1994). Das System der ägyptischen Hieroglyphenschrift in der 0.-3. Dynastie. In Göttinger Orientforschung (IV, Reihe Ägypten, Band 29). Wiesbaden: Otto Harrassowitz Verlag.

Kaiser, W., \& Dreyer, G. (1982). Umm el-Qaab: Nachuntersuchungen im frühzeitlichen Königsfriedhof. 2. Vorbericht (Vol. 38, pp. 211-269). Mainz: Mitteilungen des deutschen archäologischen Instituts Abteilung Kairo (MDAIK).

Kaplony, P. (1963). Die Innenschriften der Ägyptischen Frühzeit. Band III: Abbildungen. Wiesbaden: Otto Harrassowitz Verlag.

Krauss, R. (1997). Astronomische Konzepte und Jenseitsvorstellungen in den Pyramidentexten. Wiesbaden: Otto Harrassowitz Verlag.

Kromer, K. (1972). Österreichische Ausgrabungen in Giseh: Vorbericht über die Frühjahrskampagne 1971. Wien: Kommissionsverlag der Österreichischen Akademie der Wissenschaften.

Kurth, D., Behrmann, A., Block, A., Brech, R., Budde, D., Effland, A., von Falck, M., Felber, H., Graeff, J.-P., Koepke, S., Martinssen-von Falck, S., Pardey, E., Rüter, St., Waitkus, W., \& Woodhouse, S. (2014). Die Inschriften des Tempels von Edfu. Abteilung I Übersetzungen; Band 3. Edfou VI. Gladbeck: PeWe-Verlag.

LaViolette, P. A. (2011). Evidence for a Solar Flare Cause of the Pleistocene Mass Extinction. Radiocarbon, 53, 303-332. https://doi.org/10.1017/S0033822200056575

Lehner, M. E. (1991). Archaeology of an Image: The Great Sphinx of Giza (Volume 1). PhD Thesis, New Haven, CT: Graduate School of Yale University.

Lehner, M. E. (1992). Documentation of the Sphinx. In The First International Sympo- 
sium on the Great Sphinx, Book of Proceedings (pp. 55-107). Cairo: Egyptian Antiquities Organization Press.

Lehner, M., \& Hawass, Z. (2017). Giza and the Pyramids. The Definitive History. Chicago, IL: University of Chicago Press.

Mariette, A. (1857). Le Serapeum de Memphis. Paris: Gide. https://digi.ub.uni-heidelberg.de/diglit/mariette1882bd1/0101/text_ocr

NBC (National Broadcasting Company) (1993). The Mystery of the Sphinx (Television Documentary).

Oppenheim, L. (1956/1995). The Assyrian Dictionary (Volume 5 G). https://oi.uchicago.edu/sites/oi.uchicago.edu/files/uploads/shared/docs/cad_g.pdf

Oppenheim, L. (1965/1998). The Assyrian Dictionary (Volume 2 B). https:/oi.uchicago.edu/sites/oi.uchicago.edu/files/uploads/shared/docs/cad_b.pdf

Oppenheim, L. (1968/2004). The Assyrian Dictionary (Volume 1 A, Part II). https://oi.uchicago.edu/sites/oi.uchicago.edu/files/uploads/shared/docs/cad_a2.pdf

Oppenheim, L. (1971/2008). The Assyrian Dictionary (Volume 8 K). https://oi.uchicago.edu/sites/oi.uchicago.edu/files/uploads/shared/docs/cad_k.pdf

Oppenheim, L. (2010). The Assyrian Dictionary (Volume $20 \mathrm{U}$ and W). https://oi.uchicago.edu/sites/oi.uchicago.edu/files/uploads/shared/docs/cad_u_w.pdf

Petrie, W. M. F. (1901). The Royal Tombs of the Earliest Dynasties. Part II. Extra Plates. London: Offices of the Egypt Exploration Fund.

Reader, C. (1997). Khufu Knew the Sphinx. https://www.academia.edu/7046492/Khufu_Knew_the_Sphinx

Reader, C. (2005). A Reconciliation of the Geological and Archaeological Evidence for the Age of the Sphinx and a Revised Sequence of Development for the Giza Necropolis. In A. Cooke, \& F. C. Simpson (Eds.), Current Research in Egyptology II (pp. 47-56). Liverpool 2001, BAR International Series 1380. Oxford: BAR Publishing.

Reisner, G. A. (1912). Solving the Riddle of the Sphinx. Cosmopolitan, 53, 4-13.

Ricke, H. (1970). Der Harmarchistempel des Chefren in Giseh. Beiträge BF 10. Mainz: Rheingold Druckerei.

Schoch, R. (1992). Redating the Great Sphinx of Giza. KMT, A Modern Journal of Ancient Egypt, 3, 52-59, 66-70.

Schoch, R. M. (2012). Forgotten Civilization: The Role of Solar Outbursts in Our Past and Future. Rochester, VT: Inner Traditions.

Schoch, R. M. (2016). Ancient Fire and Lightning: Could Solar Outbursts Once Have Scorched the Giza Plateau? Atlantis Rising, No. 120, 44, 71-72.

Schoch, R. M., \& Bauval, R. (2017). Origins of the Sphinx: Celestial Guardian of Pre-Pharaonic Civilization. Rochester, VT: Inner Traditions.

Seyfzadeh, M., \& Schoch, R. M. (2018). The Inventory Stele: More Fact than Fiction. Archaeological Discovery, 6, 103-161. https://doi.org/10.4236/ad.2018.62007

Seyfzadeh, M., \& Schoch, R. M. (2019). World's First Known Written Word at Göbekli Tepe on T-Shaped Pillar 18 Means God. Archaeological Discovery, 7, 31-53. https://doi.org/10.4236/ad.2019.72003

Seyfzadeh, M., Schoch, R. M., \& Bauval, R. (2017). A New Interpretation of a Rare Old Kingdom Dual Title: The King's Chief Librarian and Guardian of the Royal Archives of Mehit. Archaeological Discovery, 5, 163-177. https://doi.org/10.4236/ad.2017.53010

Sherbiny, W. (2017). Through Hermopolitean Lenses: Studies on the So-Called Book of Two Ways in Ancient Egypt. Leiden: Brill. https://doi.org/10.1163/9789004336728 
Stadlemann, R. (2000). The Great Sphinx of Giza. In Egyptology at the Dawn of the Twenty-First Century, Proceedings of the Eighth International Conference of Egyptologists (Vol. 1, pp. 464-468). Cairo: American University in Cairo Press.

Stevenson, A. (2009). Predynastic Burials. In W. Wendrich (Ed.), UCLA Encyclopedia of Egyptology. Los Angeles, CA. https://escholarship.org/uc/item/2m3463b2

Tallet, P. (2012). Ayn Sukhna and Wadi el-Jarf: Two Newly Discovered Pharaonic Harbours on the Suez Gulf. British Museum Studies in Ancient Egypt and Sudan, 18, 147-168. https://www.britishmuseum.org/PDF/Tallet.pdf

Tristant, Y., \& Midant-Reynes, B. (2011). The Predynastic Cultures of the Nile Delta. In E. Teeter (Ed.), Before the Pyramids (pp. 45-54). Chicago, IL: Oriental Institute $\mathrm{Mu}$ seum Publications.

Van der Sluijs, M. A., \& Peratt, A. L. (2010). Searching for Rock Art Evidence for an Ancient Super Aurora. Expedition Magazine, Penn Museum, 52, 33-42.

https://www.penn.museum/documents/publications/expedition/PDFs/52-2/van\%20der \%20sluijs\%20peratt.pdf

Vygus, M. (2015). Vygus Egyptian Dictionary.

https://www.pyramidtextsonline.com/documents/VygusDictionaryApril2015.pdf

Ward, W. A. (1964). Relations between Egypt and Mesopotamia from Prehistoric Times to the End of the Middle Kingdom. Journal of the Economic and Social History of the Orient, 7, 1-45. https://doi.org/10.2307/3596078

Woodward, M. L. (2003). Between Orientalist Clichés and Images of Modernization: Photographic Practice in the Late Ottoman Era. History of Photography, 27, 263-374.

https://doi.org/10.1080/03087298.2003.10441271 


\section{Erratum}

In The Inventory Stele: More Fact than Fiction (Archaeological Discovery, 2018, Vol. 6, pp. 103-161), in the last paragraph on page 123 and in the caption to Figure 11 of that paper, we erroneously equated the three-level subterranean chamber system excavated by Selim Hassan collectively called the Osiris Shaft, the lowest level of which is also known as the Water Shaft or the Tomb of Osiris, with Campbell's Tomb excavated by Howard Vyse, whose lay-out and symbolism also invokes an Osirian character. Our interpretation of the text in that part of the paper was meant to implicate the former (the Osiris Shaft) whose age based on surface luminescence testing appears to be much older than the latter (Campbell's Tomb) attributed to the Late Period (Liritzis, I., Vafiadou, A. (2014). Surface luminescence dating of some Egyptian monuments. Journal of Cultural Heritage, Vol. 16, No. 2, pp. 134-150, Table 1). 